Sharif University of Technology
Scientia Iranica
Transactions E: Industrial Engineering
hCIENTIA

\title{
Application of grey correlation-based EDAS method for parametric optimization of non-traditional machining processes
}

\author{
P.P. Das ${ }^{\mathrm{a}}$ and S. Chakraborty ${ }^{\mathrm{b}, *}$ \\ a. Department of Mechanical Engineering, Sikkim Manipal Institute of Technology, Sikkim Manipal University, Majitar, Sikkim, \\ India. \\ b. Department of Production Engineering, Jadavpur University, Kolkata, West Bengal, India.
}

Received 4 July 2019; received in revised form 8 February 2020; accepted 1 June 2020
KEYWORDS
Non-traditional machining process; Grey correlation; EDAS;
Optimization;
Process parameter; Response.

\begin{abstract}
Higher dimensional accuracy along with better surface finish of various advanced engineering materials has turned out to be the prime desideratum for the presentday manufacturing industries. To this end, Non-Traditional Machining (NTM) processes have become quite popular because of their ability to produce intricate shape geometries on diverse difficult-to-machine materials. To allow these processes to operate at their fullest capability, it is often recommended to set their different input parameters at optimal levels. Thus, in this paper, a new technique combining grey correlation method with evaluation based on distance from average solution is applied for simultaneous optimization of three NTM processes, i.e., photochemical machining process, laser-assisted jet electrochemical machining process, and abrasive water jet drilling process. The derived optimal parametric combinations outperform those as identified by other popular multi-objective optimization techniques with respect to the considered response values. The results of analysis of variance also identify the most influencing parameters for the said NTM processes. Finally, the developed surface plots would help the process engineers investigate the effects of different NTM process parameters on the corresponding grey appraisal scores.
\end{abstract}

(C) 2022 Sharif University of Technology. All rights reserved.

\section{Introduction}

In traditional machining processes, material from the workpiece is removed in the form of chips by employing cutting forces with the help of a wedge-shaped tool. These material removal processes have numerous drawbacks, like inability to machine hard and brittle

\footnotetext{
*. Corresponding author. Tel.: +91-9831568294 E-mail address: s_chakraborty00@yahoo.co.in ( $S$. Chakraborty)
}

doi: $10.24200 /$ sci.2020.53943.3499 materials, excessive tool wear, undesirable distortion of the workpiece, formation of burr, difficulty in generating complex shape geometries, and poor surface finish. To overcome these limitations, they have now been replaced by the Non-Traditional Machining (NTM) processes [1]. Unlike the conventional machining processes, NTM processes utilize mechanical, electrical, thermal, and chemical energies or a combination of them to remove material from the workpiece. The NTM processes employing mechanical energy involve the erosion of work material using a high-velocity stream of fluid or abrasive particles, like Abrasive Jet Machining (AJM), Ultrasonic Machining (USM), 
etc. However, NTM processes including Electrical Discharge Machining (EDM), Laser Beam Machining (LBM), etc. convert electrical energy into thermal energy with high intensity to remove material from the workpiece by melting and vaporization or fusion of material. In case of chemical machining, a specific chemical acts as an etchant that removes material from the workpiece while other portions are covered by a suitable mask, e.g., Photo-Chemical Machining (PCM). Recently, hybrid NTM processes including Electro-Chemical Discharge Machining (ECDM), Abrasive Water Jet Machining (AWJM), etc. have become quite popular due to their higher machining rate and capability of providing higher Material Removal Rate (MRR). These processes combine different active energy sources in the machining zone or integrate steps of two or more machining processes or combine different processes within a single machining platform.

Contrary to the typical material removal mechanism, in NTM processes, the cutting tool needs not be harder than the workpiece material, or even it may not come in contact with the workpiece. In these processes, the material removed from the workpiece may not be in the form of chips. As in the PCM process, which utilizes chemical etching through a photo-resist stencil, material is eroded from the selected areas of the workpiece by chemical corrosion action at the atomic level. The LBM process employs thermal energy in the form of high frequency monochromatic light, causing surface heating, melting, and vaporizing of the material due to impinged photons. These NTM processes are widely used to machine various advanced engineering materials, such as nimonics, metal matrix composites, stainless steel, titanium and its alloys, etc., which have found their applications in aerospace, automobile, pharmaceutical, biotechnological, and chemical industries [2].

Selection of the most suitable combination of the input parameters for a specific NTM process is often considered a challenging task due to the availability of a large number of control parameters and conflicting responses. To exploit the fullest machining capabilities of these NTM processes, identification of the optimal parametric mix is very much desirable as a slight variation in the setting of a single parameter may adversely affect the machining process in a multifaceted way. Operators' knowledge or manufacturers' handbooks are often referred to for selection of the best parametric combination of an NTM process for a specific work material and shape feature combination. However, many a time, it has been observed that the referred parametric combination leads to a near optimal or sub-optimal solution. For a particular NTM process, the best parametric combination may differ from that provided in the manufacturer's handbook, restricting the process to operate at its fullest potential $[3,4]$.
Selection of the optimal parametric combination for an NTM process is considered as a multi-response optimization problem where a set of conflicting objectives (process outputs) needs to be simultaneously satisfied. In this direction, Grey Relational Analysis (GRA) [5,6], Weighted Aggregated Sum Product Assessment (WASPAS) [7], Multi-Objective Optimization using Ratio Analysis (MOORA) [7], Technique for Order of Preference by Similarity to Ideal Solution (TOPSIS) [8], desirability function approach [9], etc. were effectively employed by the past researchers.

Evaluation based on Distance from Average Solution (EDAS) method has recently gained popularity in solving different Multi-Criteria Decision Making (MCDM) problems [10-15]. It basically evaluates the positive and negative distances of each candidate alternative from the average solution with respect to each criterion. However, it has several weaknesses: it evaluates the alternatives depending on the distance relationships among data sequences, only considering the location links. Although the performance scores of each alternative differ from each other, the distance between the primary alternative and average alternative is equal and their alternative assessment results remain the same in this approach. Thus, it is not at all suitable to deal with varied decision-making problems because its measurement scale is distance. This method both considers the location relationships among data sequences and tracks the circumstance changes among data sequences. To overcome these problems, grey correlation method $[16,17]$ is integrated here with EDAS technique for the first time to determine the optimal parametric combinations of different NTM processes. Grey correlation method is an extension of GRA technique, which basically measures the degree of correlation among data sequences in the process of changes and development. Grey correlation method can more accurately measure the relation between data sequences even with a small volume of data in hand. It employs the similarity of the curve shape as the measurement scale (grey relational grade) and is capable to highlight the estimates of the situation changes among the data sequences. Thus, the aim of this paper is focus on the application of the Grey Correlation-based EDAS (GC-EDAS) approach to identifying the optimal parametric settings of three NTM processes, i.e., PCM, Laser-Assisted Jet Electro-Chemical Machining (LAJECM) and Abrasive Water Jet Drilling (AWJD) processes while avoiding subjectivity and irrationality in the entire selection procedure. Furthermore, the derived optimal settings are compared with those obtained by the past researchers to validate the correctness and soundness of the proposed approach.

The rest of this paper is structured as follows. Section 2 presents a detailed review of the existing literature. Section 3 presents the proposed GC-EDAS 
method. Section 4 demonstrates the application of GC-EDAS method to parametric optimization of three NTM processes. Lastly, Section 5 offers conclusions.

\section{Literature review}

Obtaining optimal combinations of different input parameters for NTM processes has been the topic of immense interest among the researchers since several years. A good number of mathematical approaches have already been proposed and efficiently applied in this direction. Recently, MCDM techniques have become much popular, being applied to various fields of engineering study and also to attaining optimal parametric combinations of different NTM processes [18-23].

While considering concentration of the etchant, etching time, and temperature of the etchant as the three input parameters of a PCM process, Agrawal and Kamble [24] implemented weighted GRA approach to obtaining the best parametric combination to optimize MRR, Surface Roughness (SR), Undercut (Uc) and Etch Factor (EF) of stainless-steel work material. Prasad et al. [7] employed WASPAS and MOORA methods to optimize different interrelated responses, such as MRR, SR, and taper angle (TAP) during AJM operation of nickel 233 alloy. Pressure, standoff distance, and average grain size were the input parameters. Ananthakumar et al. [8] adopted Response Surface Methodology (RSM) and TOPSIS to determine the optimal parametric combination for plasma arc cutting of Monel 400 superalloy, with MRR, kerf taper at top/bottom surface and heat affected zone as the multi-performance measures. Sidhu and Yazdani [25] compared the relative performance of desirability function and lexicographic goal programming approaches to attaining the optimal parametric combination of an EDM process while machining particulate-reinforced metal matrix composite materials. Chakraborty et al. [26] developed Design of Experiments (DoE)-TOPSIS method-based meta-models for identification of the optimal parametric combinations for EDM and Wire Electrical Discharge Machining (WEDM) processes. Ishfaq et al. [27] investigated the influences of some unusual parameters namely thickness of a specific layer, workpiece orientation, pressure ratio, and wire diameter on the performance of WEDM operation on stainless steel material. Application of GRA technique was observed to not only reduce the SR values on both the layers of work material, but also minimize their difference. Baghel et al. [28] studied the characteristics of a hybrid diamond grinding-assisted EDM process and endeavored to maximize MRR based on RSM technique. Chakraborty and Das [29] presented a multivariate quality loss function approach for simultaneous optimization of multiple responses of Electro-
Chemical Machining (ECM), EDM, and micro-WEDM processes.

Applications of hybrid MCDM techniques combining two or more individual methods have also gained popularity in solving various decision-making problems including selection of the optimal parametric mixes for NTM processes. Rao and Yadava [30] considered oxygen pressure, pulse width, pulse frequency, and cutting speed as the controllable parameters in a Nd:YAG laser cutting process, and later applied a hybrid Taguchi-GRA approach to determine their optimal values for minimization of kerf width, kerf taper, and kerf deviation. Tang and Du [31] combined GRA and Taguchi methods to solve a parametric optimization problem for an EDM process. It was concluded that the proposed method could efficiently identify the optimal parametric setting while machining of Ti-6Al$4 \mathrm{~V}$ alloy material. Jagadish and Ray [32] combined GRA technique with Principal Component Analysis (PCA) for obtaining the optimal parametric setting of a green EDM process. The corresponding weights of different responses were estimated based on PCA, while GRA approach would assist in identification of the best parametric mix for the said process. Nadda et al. [33] experimentally investigated the influences of different EDM process parameters such as pulseon time, pulse-off time, pulse current, and voltage on three responses including MRR, tool wear rate, and SR while machining cobalt-bonded tungsten carbide material. Analytic hierarchy process and TOPSIS methods were integrated to derive the optimal settings of the process parameters, resulting in enhanced machining performance. Considering servo voltage, wire tension, pulse-on time, and pulse-off time as the input parameters of a WEDM process, Das et al. [34] applied a hybrid grey-fuzzy approach to optimize MRR and SR values of the said process. Chakraborty et al. [35] combined GRA technique with fuzzy logic to achieve the best parametric mixes for AWJM, ECM, and USM processes.

From the review of the above-cited literature, it can be revealed that the past researchers already made efforts in obtaining optimal parametric combinations for different NTM processes using various multiobjective optimization techniques. Based on these previous research works, the following research gaps are identified:

(a) Efficiency of any machining process is usually affected by poor machining environment, resulting in worse response values. Hence, there is a need for a robust mathematical approach that can take into account the uncertainty among data sequences while providing more accurate solutions;

(b) The EDAS has several weaknesses; it evaluates 
the alternatives depending on the distance relationships among data sequences, only takes into account the location links, and makes it unsuitable to deal with complex decision-making problems.

This paper thus attempts to bridge the above-identified research gaps as follows:

(a) Owing to the drawbacks of EDAS method, a hybrid grey correlation-based EDAS method is proposed to avoid/reduce subjectivity and irrationality in the decision-making problems;

(b) It is efficient enough in identifying the optimal parametric mixes of different NTM processes while providing better response values than other optimization techniques.

Applications of grey correlation-based MCDM techniques have already been proven quite effective in solving diverse MCDM problems [36-39]. Thus, in this paper, a new hybrid approach combining grey correlation method with EDAS technique is presented to obtain the optimal parametric combinations of three NTM processes, i.e., PCM, LA-JECM, and AWJD processes.

\section{GC-EDAS approach}

\subsection{Original EDAS approach}

In this section, the original EDAS approach is presented for solving decision-making-based optimization problems in real-time machining environment. Its application consists of the following procedural steps:

Step 1: Initiation of the decision matrix $(X)$ :

$$
X=\left[x_{i j}\right]_{m \times n}=\left[\begin{array}{cccc}
x_{11} & x_{12} & \ldots & x_{1 n} \\
x_{21} & x_{22} & \ldots & x_{2 n} \\
\ldots & \ldots & \ldots & \ldots \\
x_{m 1} & x_{m 2} & \ldots & x_{m n}
\end{array}\right]
$$

where $x_{i j}$ is the performance measure of the $i$ th alternative against the $j$ th criterion, $m$ is the number of alternatives, and $n$ is the number of criteria/attributes.

Step 2: Determination of the average solution with respect to all the criteria:

$$
\bar{X}=\left[\bar{X}_{j}\right]_{1 \times n}(j=1,2, \ldots, n),
$$

where,

$$
\overline{X_{j}}=\frac{\sum_{i=1}^{m} x_{i j}}{m}(j=1,2, \ldots, n) .
$$

Step 3: Calculation of the Positive Distance from the Average (PDA) and Negative Distance from the Average (NDA) based on the type of quality characteristic (beneficial/non-beneficial) considered:

$$
\begin{aligned}
& P D A=\left[P D A_{i j}\right]_{m \times n}, \\
& N D A=\left[N D A_{i j}\right]_{m \times n}
\end{aligned}
$$

If the $j$ th response is of larger-the-better type (beneficial), then we have:

$$
\begin{aligned}
P D A_{i j} & =\frac{\max \left(0,\left(x_{i j}-\bar{X}_{j}\right)\right)}{\bar{X}_{j}}, \\
N D A_{i j} & =\frac{\max \left(0,\left(\bar{X}_{j}-x_{i j}\right)\right)}{\bar{X}_{j}} .
\end{aligned}
$$

If the $j$ th response is of smaller-the-better type (nonbeneficial), then we have:

$$
\begin{aligned}
P D A_{i j} & =\frac{\max \left(0,\left(\bar{X}_{j}-x_{i j}\right)\right)}{\bar{X}_{j}}, \\
N D A_{i j} & =\frac{\max \left(0,\left(x_{i j}-\bar{X}_{j}\right)\right)}{\bar{X}_{j}} .
\end{aligned}
$$

Step 4: Calculation of the weighted sum of PDA and NDA.

$$
\begin{aligned}
& S P_{i}=\frac{1}{m} \sum_{j=1}^{n} w_{j} P D A_{i j} \\
& S N_{i}=\frac{1}{m} \sum_{j=1}^{n} w_{j} N D A_{i j} .
\end{aligned}
$$

Step 5: Normalization values for SP and SN:

$$
\begin{aligned}
& N S P_{i}=\frac{S P_{i}}{\max _{i}\left(S P_{i}\right)}, \\
& N S N_{i}=1-\frac{S N_{i}}{\max _{i}\left(S N_{i}\right)} .
\end{aligned}
$$

Step 6: Calculation of the Appraisal Scores (AS) for all the alternatives:

$$
A S_{i}=\frac{1}{2}\left(N S P_{i}+N S N_{i}\right)
$$

where $0 \leq A S_{i} \leq 1$. A higher value of AS for a particular alternative indicates its preference over the other alternatives.

\subsection{Proposed GC-EDAS approach}

This is quite similar to the original EDAS method. Both start with the measurement of the positive distance and negative distance from the average. Their difference lies in the integration of grey correlation method to calculate Grey Correlation Coefficients (GCC) for the positive distance from the average and negative distance from the average. The steps for this approach after estimation of PDA and NDA values are explained below: 
Step 1: Computation of GCC values for the PDA $(\mathrm{GP})$ and NDA (GN):

$$
\begin{aligned}
G P_{i j} & =\frac{P D A_{\min }+\xi P D A_{\max }}{\left|P D A_{\max }-P D A_{i j}\right|+\xi P D A_{\max }}, \\
G N_{i j} & =\frac{N D A_{\min }+\xi N D A_{\max }}{\left|N D A_{\max }-N D A_{i j}\right|+\xi N D A_{\max }},
\end{aligned}
$$

where $\xi$ is the distinguishing or identification coefficient (usually $\xi=0.5$ ).

Step 2: The average weighted GCC values for the positive and negative distances can now be calculated as follows:

$$
\begin{aligned}
& G C P_{i}=\frac{1}{m} \sum_{j=1}^{n} w_{j} G P_{i j}, \\
& G C N_{i}=\frac{1}{m} \sum_{j=1}^{n} w_{j} G N_{i j},
\end{aligned}
$$

where $w_{j}$ is the weight (relative importance) of the $j$ th response.

Step 3: Normalization of the average weighted GCC values:

$$
N G C P_{i}=\frac{G C P_{i}}{\max _{i}\left(G C P_{i}\right)},
$$

$$
N G C N_{i}=1-\frac{G C N_{i}}{\max _{i}\left(G C N_{i}\right)} .
$$

Step 4: Calculation of the Grey Appraisal Scores (GAP) for all the candidate alternatives:

$$
G A P_{i}=\frac{1}{2}\left(N G C P_{i}+N G C N_{i}\right)
$$

where $0 \leq G A P_{i} \leq 1$. A higher value of GAP for a particular alternative indicates its preference over the others for the aforementioned application.

The proposed GC-EDAS method has several advantages as follows:

(a) Its application requires less information to analyze the behavior of an unknown system and is capable of obtaining an unbiased and consistent point estimator;

(b) Its takes into consideration both distance relationships and similarity correlation index among data sequences, thereby resulting in more accurate solutions.

The step-by-step application procedure of GC-EDAS approach is pictorially presented in a flowchart, as shown in Figure 1.

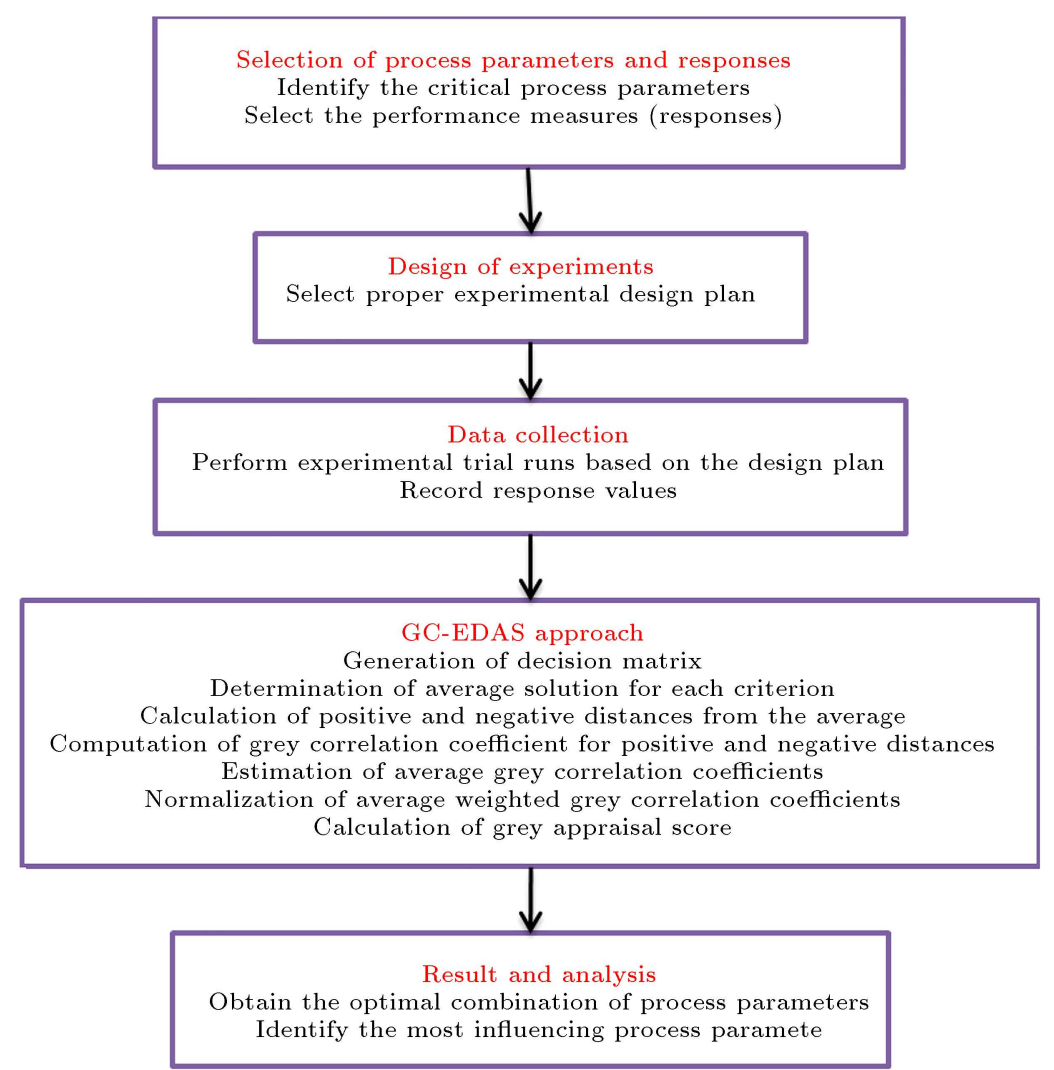

Figure 1. Flowchart of the GC-EDAS approach to parametric optimization of Non-Traditional Machining (NTM) processes. 


\section{Parametric optimization of NTM processes using GC-EDAS approach}

\subsection{PCM process}

Agrawal and Kamble [24] applied weighted GRA technique as a multi-objective optimization tool in a PCM operation on stainless steel (SS304) material considering ferric chloride as the etchant to attain accurate dimensions of the workpiece with better shape features. Employing Taguchi's $L_{27}$ orthogonal array, 27 experiments were performed, taking concentration of the etchant, time of etching, and temperature of the etchant as the input parameters. A three-level variation for each of those parameters was considered based on the available settings of the PCM setup. The considered process parameters along with their levels are provided in Table 1 . On the other hand, SR (in $\mu \mathrm{m}$ ), Uc (in $\mathrm{mm}$ ), MRR (in $\mathrm{mm}^{3} / \mathrm{min}$ ), and EF were the responses. The $\mathrm{SR}$ values were measured using Mitutoyo SR tester, and Uc was estimated as the difference between the outer and inner radii of the machined hole. The MRR was obtained as the volume (depth of cut $\times$ area under etching) of material removed with respect to the considered machining time (in min), while EF was estimated taking the ratio of depth of cut to Uc. The detailed experimental design plan along with the measured responses is given in Table 2. Among the four responses, MRR is the only larger-the-better type of quality characteristic, while the remaining three are smaller-the-better types of characteristics.

Based on the type of the response and employing Eqs. (1)-(7), the PDA and NDA are now calculated,

Table 1. Process parameters with levels for the Photo-Chemical Machining (PCM) process [24].

\begin{tabular}{lcccc}
\hline \multicolumn{1}{c}{ Process parameter } & Unit & Level 1 & Level 2 & Level 3 \\
\hline Concentration of the etchant (A) & $\mathrm{g} / 1$ & 650 & 750 & 850 \\
Time of etching (B) & $\min$ & 30 & 40 & 50 \\
Temperature of the etchant (C) & ${ }^{\circ} \mathrm{C}$ & 50 & 60 & 70 \\
\hline
\end{tabular}

Table 2. Experimental details for Photo-Chemical Machining (PCM) the process [24].

\begin{tabular}{cccccccc}
\hline Run & A & B & C & SR & Uc & MRR & EF \\
\hline 1 & 650 & 30 & 50 & 1.683 & 0.0270 & 3.140 & 1.48 \\
2 & 650 & 30 & 60 & 0.741 & 0.0473 & 6.044 & 1.62 \\
3 & 650 & 30 & 70 & 0.707 & 0.0623 & 6.280 & 1.52 \\
4 & 650 & 40 & 50 & 1.066 & 0.0304 & 3.297 & 1.41 \\
5 & 650 & 40 & 60 & 2.287 & 0.0413 & 4.553 & 1.40 \\
6 & 650 & 40 & 70 & 0.573 & 0.0523 & 7.928 & 1.93 \\
7 & 650 & 50 & 50 & 0.747 & 0.0930 & 7.614 & 1.03 \\
8 & 650 & 50 & 60 & 0.980 & 0.0944 & 7.771 & 1.04 \\
9 & 650 & 50 & 70 & 1.402 & 0.0573 & 7.928 & 1.76 \\
10 & 750 & 30 & 50 & 0.877 & 0.0677 & 5.338 & 1.00 \\
11 & 750 & 30 & 60 & 1.354 & 0.0736 & 7.693 & 1.33 \\
12 & 750 & 30 & 70 & 0.970 & 0.0964 & 8.870 & 1.17 \\
13 & 750 & 40 & 50 & 1.155 & 0.0772 & 6.410 & 1.04 \\
14 & 750 & 40 & 60 & 0.984 & 0.0821 & 7.879 & 1.14 \\
15 & 750 & 40 & 70 & 0.202 & 0.0710 & 8.910 & 1.71 \\
16 & 750 & 50 & 50 & 0.968 & 0.0770 & 6.672 & 1.10 \\
17 & 750 & 50 & 60 & 1.082 & 0.0725 & 7.457 & 1.31 \\
18 & 750 & 50 & 70 & 2.258 & 0.0850 & 7.693 & 1.15 \\
19 & 850 & 30 & 50 & 0.864 & 0.0811 & 7.771 & 1.22 \\
20 & 850 & 30 & 60 & 1.006 & 0.0670 & 5.479 & 1.47 \\
21 & 850 & 30 & 70 & 0.884 & 0.0827 & 8.478 & 1.30 \\
22 & 850 & 40 & 50 & 0.859 & 0.0661 & 5.700 & 1.10 \\
23 & 850 & 40 & 60 & 1.042 & 0.0460 & 6.280 & 1.73 \\
24 & 850 & 40 & 70 & 1.615 & 0.0462 & 6.829 & 1.89 \\
25 & 850 & 50 & 50 & 0.098 & 0.0691 & 7.693 & 1.41 \\
26 & 850 & 50 & 60 & 0.117 & 0.0810 & 9.184 & 1.44 \\
27 & 850 & 50 & 70 & 0.218 & 0.0940 & 9.263 & 1.40 \\
\hline & & & & & & & \\
\hline
\end{tabular}


Table 3. Positive and negative distances from the average for the Photo-Chemical Machining (PCM) process.

\begin{tabular}{|c|c|c|c|c|c|c|c|c|}
\hline \multirow[b]{2}{*}{ Run } & \multicolumn{4}{|c|}{ PDA } & \multicolumn{4}{|c|}{ NDA } \\
\hline & SR & Uc & MRR & EF & SR & Uc & MRR & EF \\
\hline 1 & 0 & 0.6040 & 0 & 0.0771 & 0.6994 & 0 & 0.5494 & 0 \\
\hline 2 & 0.2518 & 0.3063 & 0 & 0.1790 & 0 & 0 & 0.1327 & 0 \\
\hline 3 & 0.2861 & 0.0863 & 0 & 0.1062 & 0 & 0 & 0.0988 & 0 \\
\hline 4 & 0 & 0.5542 & 0 & 0.0261 & 0.0764 & 0 & 0.5269 & 0 \\
\hline 5 & 0 & 0.3943 & 0 & 0.0189 & 1.3093 & 0 & 0.3466 & 0 \\
\hline 6 & 0.4214 & 0.2330 & 0.1377 & 0.4046 & 0 & 0 & 0 & 0 \\
\hline 7 & 0.2457 & 0 & 0.0926 & 0 & 0 & 0.3639 & 0 & 0.2504 \\
\hline 8 & 0.0104 & 0 & 0.1151 & 0 & 0 & 0.3845 & 0 & 0.2431 \\
\hline 9 & 0 & 0.1596 & 0.1377 & 0.2809 & 0.4157 & 0 & 0 & 0 \\
\hline 10 & 0.1144 & 0.0071 & 0 & 0 & 0 & 0 & 0.2340 & 0.2722 \\
\hline 11 & 0 & 0 & 0.1039 & 0 & 0.3672 & 0.0794 & 0 & 0.0321 \\
\hline 12 & 0.0205 & 0 & 0.2728 & 0 & 0 & 0.4138 & 0 & 0.1485 \\
\hline 13 & 0 & 0 & 0 & 0 & 0.1663 & 0.1322 & 0.0802 & 0.2431 \\
\hline 14 & 0.0064 & 0 & 0.1306 & 0 & 0 & 0.2041 & 0 & 0.1704 \\
\hline 15 & 0.7960 & 0 & 0.2786 & 0.2445 & 0 & 0.0413 & 0 & 0 \\
\hline 16 & 0.0226 & 0 & 0 & 0 & 0 & 0.1293 & 0.0426 & 0.1995 \\
\hline 17 & 0 & 0 & 0.0701 & 0 & 0.0926 & 0.0633 & 0 & 0.0466 \\
\hline 18 & 0 & 0 & 0.1039 & 0 & 1.28 & 0.2466 & 0 & 0.1631 \\
\hline 19 & 0.1276 & 0 & 0.1151 & 0 & 0 & 0.1894 & 0 & 0.1121 \\
\hline 20 & 0 & 0.0174 & 0 & 0.0698 & 0.0158 & 0 & 0.2138 & 0 \\
\hline 21 & 0.1074 & 0 & 0.2166 & 0 & 0 & 0.2129 & 0 & 0.0539 \\
\hline 22 & 0.1326 & 0.0306 & 0 & 0 & 0 & 0 & 0.1821 & 0.1995 \\
\hline 23 & 0 & 0.3254 & 0 & 0.2590 & 0.0522 & 0 & 0.0988 & 0 \\
\hline 24 & 0 & 0.3224 & 0 & 0.3755 & 0.6308 & 0 & 0.0200 & 0 \\
\hline 25 & 0.9010 & 0 & 0.1039 & 0.0261 & 0 & 0.0134 & 0 & 0 \\
\hline 26 & 0.8819 & 0 & 0.3179 & 0.0480 & 0 & 0.1879 & 0 & 0 \\
\hline 27 & 0.7799 & 0 & 0.3292 & 0.0189 & 0 & 0.3786 & 0 & 0 \\
\hline
\end{tabular}

as shown in Table 3. The corresponding GCC values for the positive and negative distances from the average are then estimated using Eqs. (13) and (14), as presented in Table 4 . The weights for all the four responses are considered to be the same as it is assumed that they are equally important from the real-time machining point of view. Utilizing Eqs. (15) and (16), the average weighted GCC values are computed, and they are further normalized within a range of 0 to 1 using Eqs. (17) and (18). The average weighted GRC and their normalized values are also presented in Table 4. Finally, the GAP for each experimental run (alternative) is calculated based on Eq. (19), as given in Table 4. From this table, it can be clearly noticed that the experimental trial number 15 has the highest GAP score of 0.6934 and the corresponding parametric combination of $A_{2} B_{2} C_{3}$ is identified to be the best among all the 27 trials, followed by the experiment

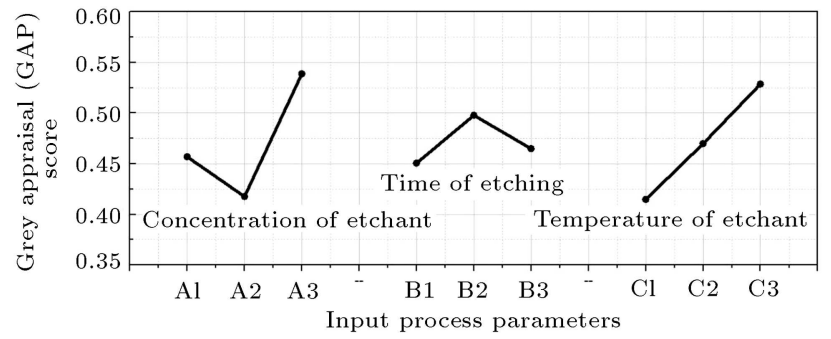

Figure 2. Response graph for Grey Appraisal Score (GAP) for the Photo-Chemical Machining (PCM) process.

runs 26 and 6 with GAP scores of 0.6919 and 0.6844 , respectively.

The response table and the corresponding response plot are provided in Table 5 and Figure 2, respectively. They are obtained while calculating the average GAP scores at the corresponding operating levels of the considered PCM process. Based on 
Table 4. Grey Correlation Coefficient (GCC) values for positive and negative distances, average weighted and normalized GCC values, and GAP scores for the Photo-Chemical Machining (PCM) process.

\begin{tabular}{|c|c|c|c|c|c|c|c|c|c|c|c|c|c|}
\hline \multirow[b]{2}{*}{ Run } & \multicolumn{4}{|c|}{ GP } & \multicolumn{4}{|c|}{ GN } & \multirow{2}{*}{ GCP } & \multirow{2}{*}{ GCN } & \multirow{2}{*}{ NGCP } & \multirow{2}{*}{ NGCN } & \multirow{2}{*}{$\begin{array}{l}\text { GAP } \\
\text { score }\end{array}$} \\
\hline & $\mathbf{S R}$ & Uc & MRR & EF & SR & Uc & MRR & EF & & & & & \\
\hline 1 & 0.3333 & 1 & 0.3333 & 0.3818 & 0.5177 & 0.3333 & 1 & 0.3333 & 0.5121 & 0.5461 & 0.7909 & 0.0893 & 0.4401 \\
\hline 2 & 0.4096 & 0.5036 & 0.3333 & 0.4728 & 0.3333 & 0.3333 & 0.3973 & 0.3333 & 0.4298 & 0.3493 & 0.6638 & 0.4174 & 0.5406 \\
\hline 3 & 0.4228 & 0.3684 & 0.3333 & 0.4040 & 0.3333 & 0.3333 & 0.3788 & 0.3333 & 0.3822 & 0.3447 & 0.5902 & 0.4252 & 0.5077 \\
\hline 4 & 0.3333 & 0.8583 & 0.3333 & 0.3483 & 0.3468 & 0.3333 & 0.9242 & 0.3333 & 0.4683 & 0.4844 & 0.7233 & 0.1921 & 0.4577 \\
\hline 5 & 0.3333 & 0.5902 & 0.3333 & 0.3440 & 1 & 0.3333 & 0.5753 & 0.3333 & 0.4002 & 0.5605 & 0.6181 & 0.0653 & 0.3417 \\
\hline 6 & 0.4843 & 0.4487 & 0.4622 & 1 & 0.3333 & 0.3333 & 0.3333 & 0.3333 & 0.5988 & 0.3333 & 0.9248 & 0.4441 & 0.6844 \\
\hline 7 & 0.4074 & 0.3333 & 0.4103 & 0.3333 & 0.3333 & 0.8058 & 0.3333 & 0.8618 & 0.3711 & 0.5836 & 0.5731 & 0.0268 & 0.3000 \\
\hline 8 & 0.3359 & 0.3333 & 0.4347 & 0.3333 & 0.3333 & 0.8758 & 0.3333 & 0.8238 & 0.3593 & 0.5916 & 0.5549 & 0.0134 & 0.2842 \\
\hline 9 & 0.3333 & 0.4046 & 0.4622 & 0.6205 & 0.4228 & 0.3333 & 0.3333 & 0.3333 & 0.4552 & 0.3557 & 29 & 0.4068 & 0.5549 \\
\hline 10 & 0.3642 & 0.3360 & 0.3333 & 0.3333 & 0.3333 & 0.3333 & 0.4655 & 1 & 0.3417 & 0.5330 & 0.5277 & 0.1111 & 0.3194 \\
\hline 11 & 0.3333 & 0.3333 & 0.4222 & 0.3333 & 0.4100 & 0.3822 & 0.3333 & 0.3617 & 0.3555 & 0.3718 & 0.5491 & 0.3799 & 0.4645 \\
\hline 12 & 0.3385 & 0.3333 & 0.7448 & 0.3333 & 0.3333 & 1 & 0.3333 & 0.5239 & 0.4375 & 0.5476 & 0.6757 & 0.0867 & 0.3812 \\
\hline 13 & 0.3333 & 0.3333 & 0.3333 & 0.3333 & 0.3642 & 0.4236 & 0.3693 & 0.8238 & 0.3333 & 0.4952 & 0.5148 & 0.1742 & 0.3445 \\
\hline 14 & 0.3349 & 0.3333 & 0.4532 & 0.3333 & 0.3333 & 0.4966 & 0.3333 & 0.5719 & 0.3637 & 0.4338 & 0.5617 & 0.2766 & 0.4191 \\
\hline 15 & 0.8110 & 0.3333 & 0.7647 & 0.5582 & 0.3333 & 0.3571 & 0.3333 & 0.3333 & 0.6168 & 0.3393 & 0.9526 & 0.4342 & 0.6934 \\
\hline 16 & 0.3390 & 0.3333 & 0.3333 & 0.3333 & 0.3333 & 0.4210 & 0.3515 & 0.6516 & 0.3347 & 0.4394 & 0.5170 & 0.2673 & 0.3921 \\
\hline 17 & 0.3333 & 0.3333 & 0.3885 & 0.3333 & 0.3498 & 0.3712 & 0.3333 & 0.3763 & 0.3471 & 0.3577 & 0.5361 & 0.4035 & 0.4698 \\
\hline 18 & 0.3333 & 0.3333 & 0.4222 & 0.3333 & 0.9572 & 0.5531 & 0.3333 & 0.5549 & 0.3555 & 0.5996 & 0.5491 & 0 & 0.2746 \\
\hline 19 & 0.3681 & 0.3333 & 0.4347 & 0.3333 & 0.3333 & 0.4797 & 0.3333 & 0.4595 & 0.3674 & 0.4015 & 0.5673 & 0.3305 & 0.4489 \\
\hline 20 & 0.3333 & 0.3399 & 0.3333 & 0.3767 & 0.3360 & 0.3333 & 0.4501 & 0.3333 & 0.3458 & 0.3632 & 0.5340 & 0.3943 & 0.4642 \\
\hline 21 & 0.3621 & 0.3333 & 0.5937 & 0.3333 & 0.3333 & 0.5073 & 0.3333 & 0.3840 & 0.4056 & 0.3895 & 0.6264 & 0.3504 & 0.4884 \\
\hline 22 & 0.3696 & 0.3450 & 0.3333 & 0.3333 & 0.3333 & 0.3333 & 0.4278 & 0.6516 & 0.3453 & 0.4365 & 0.5333 & 0.2720 & 0.4026 \\
\hline 23 & 0.3333 & 0.5201 & 0.3333 & 0.5816 & 0.3424 & 0.3333 & 0.3788 & 0.3333 & 0.4421 & 0.3470 & 0.6828 & 0.4214 & 0.5521 \\
\hline 24 & 0.3333 & 0.5175 & 0.3333 & 0.8742 & 0.4910 & 0.3333 & 0.3416 & 0.3333 & 0.5146 & 0.3748 & 0.7947 & 0.3749 & 0.5848 \\
\hline 25 & 1 & 0.3333 & 0.4222 & 0.3483 & 0.3333 & 0.3407 & 0.3333 & 0.3333 & 0.5260 & 0.3352 & 0.8123 & 0.4410 & 0.6267 \\
\hline 26 & 0.9592 & 0.3333 & 0.9356 & 0.3619 & 0.3333 & 0.4781 & 0.3333 & 0.3333 & 0.6475 & 0.3695 & 1 & 0.3837 & 0.6919 \\
\hline 27 & 0.7880 & 0.3333 & 1 & 0.3440 & 0.3333 & 0.8546 & 0.3333 & 0.3333 & 0.6164 & 0.4637 & 0.9519 & 0.2268 & 0.5893 \\
\hline
\end{tabular}

Table 5. Response table for GAP scores for the Photo-Chemical Machining (PCM) process.

\begin{tabular}{lcccccc}
\hline \multirow{2}{*}{ Process parameter } & \multicolumn{3}{c}{ Level } & \multirow{2}{*}{ Max-min } & \multirow{2}{*}{ Rank } \\
\cline { 2 - 4 } & Level 1 & Level 2 & Level 3 & & \\
\hline Concentration of the etchant & 0.4568 & 0.4176 & $\mathbf{0 . 5 3 8 8}$ & 0.1212 & 1 \\
Time of etching & 0.4506 & $\mathbf{0 . 4 9 7 8}$ & 0.4648 & 0.0472 & 3 \\
Temperature of the etchant & 0.4147 & 0.4698 & $\mathbf{0 . 5 2 8 7}$ & 0.1140 & 2 \\
\hline
\end{tabular}

Table 6. ANOVA results of the Photo-Chemical Machining (PCM) process.

\begin{tabular}{lccccc}
\hline \multicolumn{1}{c}{ Source } & DoF & Adj SS & Adj MS & $\boldsymbol{F}$ value & Contribution (\%) \\
\hline Concentration of the etchant & 2 & 0.05904 & 0.029520 & 14.52 & 41.11 \\
Time of etching & 2 & 0.01319 & 0.006594 & 3.24 & 9.18 \\
Temperature of the etchant & 2 & 0.03073 & 0.015366 & 7.56 & 21.40 \\
Error & 20 & 0.04066 & 0.002033 & - & 28.31 \\
Total & 26 & 0.14362 & - & - & - \\
\hline
\end{tabular}

the average values of GAP score, the best operating levels of the PCM process are identified in Table 5, as indicated in bold face. Thus, in order to explore the fullest machining potential of the PCM process, the optimal parametric combination needs to be set as concentration of the etchant $=850 \mathrm{~g} / \mathrm{l}$, time of etching $=40 \mathrm{~min}$, and temperature of the etchant $=70^{\circ} \mathrm{C}$, which can also be represented as $A_{3} B_{2} C_{3}$. The maxmin column in Table 5 identifies concentration of the etchant as the most influencing PCM process parameter, followed by temperature of the etchant, which can be validated based on their steep slopes in Figure 2. Moreover, the analysis of variance (ANOVA) results, as provided in Table 6, also confirm concentration of the etchant as the most influencing PCM process parameter with a contribution of $41.11 \%$ in attaining the GAP scores, followed by temperature of the etchant (21.40\%). 
Table 7. Predicted response values for the Photo-Chemical Machining (PCM) process.

\begin{tabular}{lcccc}
\hline \multicolumn{1}{c}{ Optimization approach } & SR & Uc & MRR & EF \\
\hline GC-EDAS approach $\left(A_{3} B_{2} C_{3}\right)$ & 0.187 & 0.0615 & 12.931 & 1.6525 \\
Weighted GRA technique $\left(A_{2} B_{2} C_{3}\right)[24]$ & 0.202 & 0.0710 & 8.91 & 1.71 \\
Improvement (\%) & 32.13 & 68.31 & 27.82 & 14.65 \\
\hline
\end{tabular}

Thus, from the above analysis, it can be revealed that the experiment number $15\left(A_{2} B_{2} C_{3}\right)$ is the best combination of process parameters, while $A_{3} B_{2} C_{3}$ is observed to be the most favorable parametric mix for the considered PCM process based on the response graph. The parametric combination derived from the response graph differs from that of the experiment trial 15 only with respect to concentration of the etchant. It is due to the reason that the average value of GAP score for experiments with level 3 is more than that of experiments with level 2. Thus, there is a greater chance of achieving higher GAP score at level 3 than that at level 2 . Hence, it is always recommended to apply the said PCM process in an optimal parametric setting of $A_{3} B_{2} C_{3}$ instead of $A_{2} B_{2} C_{3}$ to ensure enhanced machining performance. Agrawal and Kamble [24] observed that with increment in concentration of the etchant, both MRR and SR (the most important responses from the practical machining point of view) would tend to increase. The MRR value increased from $3.8465 \mathrm{~mm}^{3} / \mathrm{min}$ to $8.71 \mathrm{~mm}^{3} / \mathrm{min}$ and SR increased from $3.184 \mu \mathrm{m}$ to $5.847 \mu \mathrm{m} \mathrm{up}$ to an etchant concentration of $650 \mathrm{~g} / \mathrm{l}$. However, a further increase in etchant concentration would cause a decrease in SR up to $1.2 \mu \mathrm{m}$ at $850 \mathrm{~g} / \mathrm{l}$. Higher concentration of etchant would be responsible for the availability of a larger number of ferric ions, causing an increase in reaction rate. The etchant would become more viscous at a higher concentration affecting both MRR and SR values. On the other hand, applying weighted GRA technique, Agrawal and Kamble [24] obtained the optimal parametric mix as $A_{2} B_{2} C_{3}$. Now, in order to validate the superiority of the new parametric combination $\left(A_{3} B_{2} C_{3}\right)$ over $A_{2} B_{2} C_{3}$, the following regression equations are established considering the main and interactive effects of various PCM process parameters:

$$
\begin{aligned}
S R= & -5.9+0.0207 \times A+0.108 \times B-0.066 C \\
& -0.000016 \times A^{2}-0.00145 \times B^{2}-0.00113 \\
& \times C^{2}-0.000208 \times A \times B+0.000142 \\
& \times A \times C+0.00244 \times B \times C \\
U c= & -0.975+0.002682 \times A-0.00347 \times B \\
& +0.00184 \times C-0.000001 \times A^{2}+0.000168
\end{aligned}
$$

$$
\times B^{2}+0.000014 \times C^{2}-0.000008 \times A
$$$$
\times B-0.000007 \times A \times C-0.000057 \times B \times C,
$$

$$
\begin{aligned}
M R R= & -66.2+0.1467 \times A-0.151 \times B+0.469 \\
& \times C-0.000070 \times A^{2}+0.00822 \times B^{2} \\
& +0.00063 \times C^{2}-0.000286 \times A \times B-0.0003 \\
& \times A \times C-0.00373 \times B \times C,
\end{aligned}
$$

$$
E F=12.48-0.0369 \times A+0.0389 \times B+0.050
$$

$$
\begin{aligned}
& \times C+0.000024 \times A^{2}-0.001639 \times B^{2} \\
& -0.000189 \times C^{2}+0.000088 \times A \times B \\
& -0.000036 \times A \times C+0.0003 \times B \times C .
\end{aligned}
$$

Based on these regression equations, a comparison between the predicted response values derived in the obtained optimal parametric combination and that of Agrawal and Kamble [24] is presented in Table 7. As demonstrated in this table, the optimal parametric mix obtained using the proposed GC-EDAS approach is superior to that of Agrawal and Kamble [24], resulting in improvements of $32.13 \%, 68.31 \%, 27.82 \%$, and $14.65 \%$ in the values of SR, Uc, MRR, and EF, respectively. A particular parametric optimization problem can be solved using different approaches having varying mathematical complexities. The treatments of those approaches are also vulnerable to the problem characteristics. Hence, it is always recommended that the achievable response values in different parametric settings for the considered PCM process are compared and the method that provides the best mix is identified.

Another regression model relating the input PCM process parameters to GAP score is developed and based on this model, the corresponding surface plots are generated in Figure 3. These plots would assist the process engineer in determining the corresponding GAP score for any combination of PCM process parameters.

GAP score $=10.28-0.0206 \times A-0.166 \times B$

$$
\begin{aligned}
& -0.071 \times C+0.000008 \times A^{2}-0.000401 \\
& \times B^{2}+0.000019 \times C^{2}+0.000269 \times A
\end{aligned}
$$




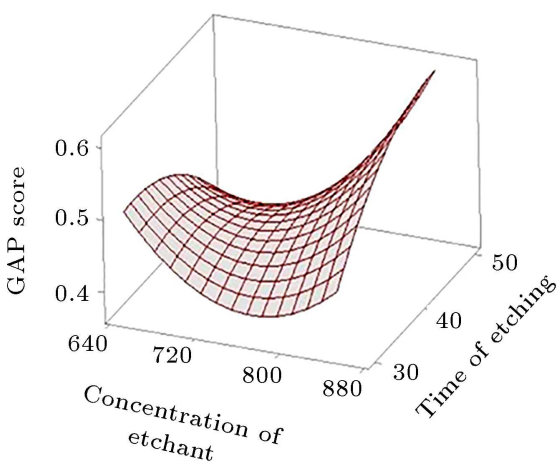

(a) GAP score vs. concentration of the etchant, time of etching

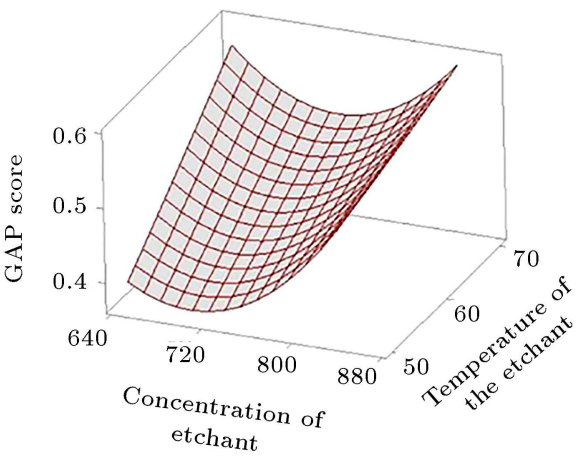

(b) GAP score vs. concentration of the etchant, temperature of the etchant

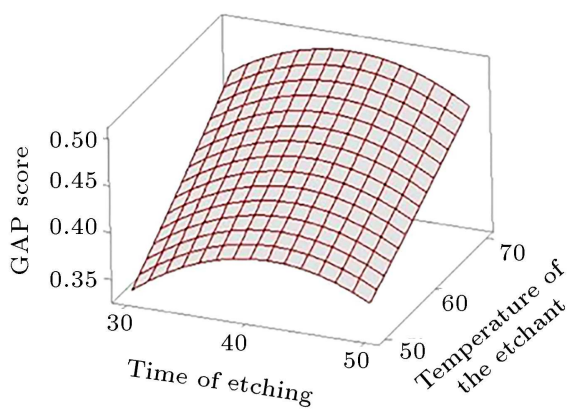

(c) GAP score vs. temperature of the etchant, time of etching

Figure 3. Surface plots showing the effects of different Photo-Chemical Machining (PCM) process parameters on GAP score.

Table 8. Process parameters with their levels for the Laser-Assisted Jet Electro-Chemical Machining (LA-JECM) process $[40]$.

\begin{tabular}{lccccc}
\hline Process parameter & Unit & Level 1 & Level 2 & Level 3 & Level 4 \\
\hline Supply voltage (A) & $\mathrm{V}$ & 80 & 120 & 160 & 200 \\
Electrolyte concentration (B) & $\mathrm{g} / 1$ & 20 & 40 & 60 & 80 \\
Inter-electrode gap (C) & $\mathrm{Mm}$ & 2 & 3 & 4 & 5 \\
Duty cycle (D) & $\%$ & 60 & 70 & 80 & 90 \\
\hline
\end{tabular}

$$
\begin{aligned}
& \times B+0.000102 \times A \times C+0.00242 \times B \\
& \times C-0.000003 \times A \times B \times C .
\end{aligned}
$$

\subsection{LA-JECM process}

Malik and Manna [40] developed a hybrid LA-JECM process for micro-drilling operation on Inconel 718 work material. Supply voltage, electrolyte concentration, inter-electrode gap, and duty cycle were considered as the four input parameters along with four level variations in each, as shown in Table 8 . To obtain the optimal parametric combination for the said LA-JECM process, Malik and Manna [40] applied GRA technique to simultaneous optimization of $\mathrm{MRR}$ (in $\mathrm{mg} / \mathrm{min}$ ), TAP (in degree), and SR (in $\mu \mathrm{m}$ ) as the responses. Among those responses, MRR is the only larger-the- better quality characteristic, and TAP and SR are the smaller-the-better quality characteristics. Based on Taguchi's $L_{16}$ orthogonal array design plan, Malik and Manna [40] conducted 16 experiments and measured the corresponding response values, as provided in Table 9. Like the previous example, for the LA-JECM process, the PDA, NDA, and the corresponding GCC values are also computed in Table 10. Table 11 shows the average weighted and normalized GCC values as well as the related GAP scores for the considered LA-JECM process. With the highest GAP score of 0.7935 , the experimental run number $14\left(A_{4} B_{2} C_{3} D_{1}\right)$ is established as the best trial among the 16 conducted experiments.

Table 12 and Figure 4 present the corresponding response table and response graph, respectively, based on the estimated GAP scores. Thus, to operate the LA- 
Table 9. Experimental details of the Laser-Assisted Jet Electro-Chemical Machining (LA-JECM) process [40].

\begin{tabular}{cccccccc}
\hline Run & A & B & C & D & MRR & TAP & SR \\
\hline 1 & 80 & 20 & 2 & 60 & 1.42 & 3.83 & 7.14 \\
2 & 80 & 40 & 3 & 70 & 1.41 & 5.52 & 5.52 \\
3 & 80 & 60 & 4 & 80 & 1.71 & 5.56 & 8.58 \\
4 & 80 & 80 & 5 & 90 & 1.82 & 12.47 & 11.67 \\
5 & 120 & 20 & 3 & 80 & 2.52 & 6.69 & 8.82 \\
6 & 120 & 40 & 2 & 90 & 4.85 & 7.90 & 10.21 \\
7 & 120 & 60 & 5 & 60 & 0.96 & 7.26 & 8.27 \\
8 & 120 & 80 & 4 & 70 & 2.51 & 6.24 & 7.20 \\
9 & 160 & 20 & 4 & 90 & 3.09 & 7.11 & 9.91 \\
10 & 160 & 40 & 5 & 80 & 1.90 & 8.66 & 9.62 \\
11 & 160 & 60 & 2 & 70 & 4.93 & 6.87 & 9.02 \\
12 & 160 & 80 & 3 & 60 & 3.81 & 5.46 & 8.67 \\
13 & 200 & 20 & 5 & 70 & 1.47 & 7.30 & 6.22 \\
14 & 200 & 40 & 4 & 60 & 2.67 & 5.57 & 5.01 \\
15 & 200 & 60 & 3 & 90 & 6.10 & 7.85 & 11.71 \\
16 & 200 & 80 & 2 & 80 & 6.59 & 10.66 & 11.05 \\
\hline
\end{tabular}

Table 10. Positive and negative distances from the average along with their Grey Correlation Coefficient (GCC) values for the Laser-Assisted Jet Electro-Chemical Machining (LA-JECM) process.

\begin{tabular}{|c|c|c|c|c|c|c|c|c|c|c|c|c|}
\hline \multirow[t]{2}{*}{ Run } & \multicolumn{3}{|c|}{ PDA } & \multicolumn{3}{|c|}{ NDA } & \multicolumn{3}{|c|}{ GP } & \multicolumn{3}{|c|}{ GN } \\
\hline & MRR & TAP & SR & MRR & TAP & SR & MRR & TAP & SR & MRR & TAP & SR \\
\hline 1 & 0 & 0.4669 & 0.1759 & 0.5243 & 0 & 0 & 0.3333 & 1 & 0.4617 & 0.6876 & 0.3333 & 0.3333 \\
\hline 2 & 0 & 0.2317 & 0.3629 & 0.5276 & 0 & 0 & 0.3333 & 0.4981 & 0.7818 & 0.6923 & 0.3333 & 0.3333 \\
\hline 3 & 0 & 0.2261 & 0.0097 & 0.4271 & 0 & 0 & 0.3333 & 0.4922 & 0.3385 & 0.5745 & 0.3333 & 0.3333 \\
\hline 4 & 0 & 0 & 0 & 0.3903 & 0.7357 & 0.3470 & 0.3333 & 0.3333 & 0.3333 & 0.5407 & 1 & 0.9744 \\
\hline 5 & 0 & 0.0688 & 0 & 0.1558 & 0 & 0.0180 & 0.3333 & 0.3697 & 0.3333 & 0.3936 & 0.3333 & 0.3451 \\
\hline 6 & 0.6248 & 0 & 0 & 0 & 0.0996 & 0.1785 & 0.5088 & 0.3333 & 0.3333 & 0.3333 & 0.3664 & 0.5038 \\
\hline 7 & 0 & 0 & 0.0454 & 0.6784 & 0.0105 & 0 & 0.3333 & 0.3333 & 0.3591 & 1 & 0.3365 & 0.3333 \\
\hline 8 & 0 & 0.1314 & 0.1690 & 0.1591 & 0 & 0 & 0.3333 & 0.4104 & 0.4548 & 0.3951 & 0.3333 & 0.3333 \\
\hline 9 & 0.0352 & 0.0104 & 0 & 0 & 0 & 0.1438 & 0.3399 & 0.3383 & 0.3333 & 0.3333 & 0.3333 & 0.4583 \\
\hline 10 & 0 & 0 & 0 & 0.3635 & 0.2054 & 0.1104 & 0.3333 & 0.3333 & 0.3333 & 0.5186 & 0.4096 & 0.4216 \\
\hline 11 & 0.6516 & 0.0438 & 0 & 0 & 0 & 0.0411 & 0.5206 & 0.3555 & 0.3333 & 0.3333 & 0.3333 & 0.3615 \\
\hline 12 & 0.2764 & 0.2400 & 0 & 0 & 0 & 0.0007 & 0.3933 & 0.5071 & 0.3333 & 0.3333 & 0.3333 & 0.3338 \\
\hline 13 & 0 & 0 & 0.2821 & 0.5075 & 0.0161 & 0 & 0.3333 & 0.3333 & 0.6016 & 0.6650 & 0.3383 & 0.3333 \\
\hline 14 & 0 & 0.2247 & 0.4217 & 0.1055 & 0 & 0 & 0.3333 & 0.4908 & 1 & 0.3719 & 0.3333 & 0.3333 \\
\hline 15 & 1.0436 & 0 & 0 & 0 & 0.0926 & 0.3516 & 0.7863 & 0.3333 & 0.3333 & 0.3333 & 0.3639 & 1 \\
\hline 16 & 1.2077 & 0 & 0 & 0 & 0.4838 & 0.2754 & 1 & 0.3333 & 0.3333 & 0.3333 & 0.5935 & 0.6977 \\
\hline
\end{tabular}

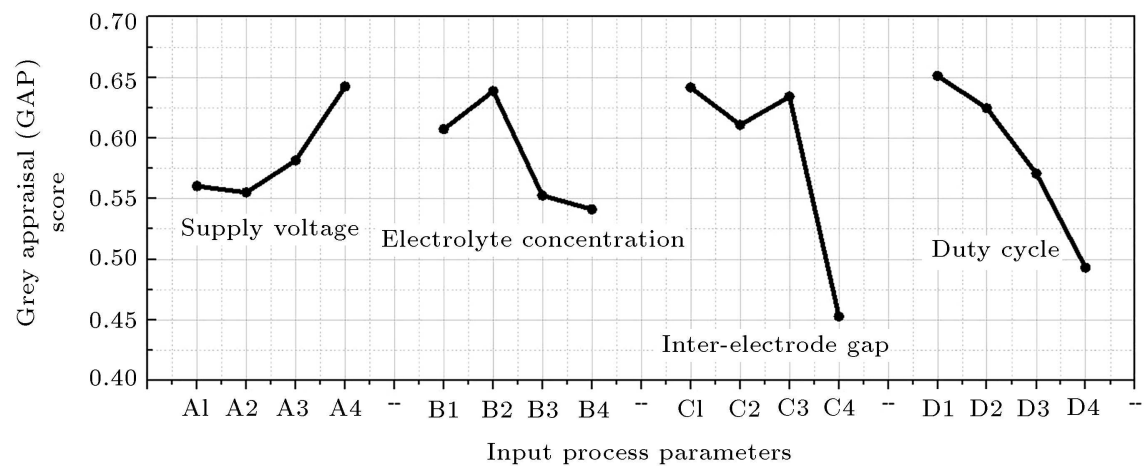

Figure 4. Response graph for GAP score for the Laser-Assisted Jet Electro-Chemical Machining (LA-JECM) process. 
Table 11. Average weighted and normalized Grey Correlation Coefficient (GCC) values as well as the GAP score for the Laser-Assisted Jet Electro-Chemical Machining (LA-JECM) process.

\begin{tabular}{cccccc}
\hline Run & GCP & GCN & NGCP & NGCN & $\begin{array}{c}\text { GAP } \\
\text { score }\end{array}$ \\
\hline 1 & 0.5983 & 0.4514 & 0.9840 & 0.4615 & 0.7228 \\
2 & 0.5377 & 0.4530 & 0.8844 & 0.4597 & 0.6720 \\
3 & 0.3880 & 0.4137 & 0.6382 & 0.5065 & 0.5723 \\
4 & 0.3333 & 0.8384 & 0.5482 & 0 & 0.2741 \\
5 & 0.3454 & 0.3574 & 0.5681 & 0.5738 & 0.5709 \\
6 & 0.3918 & 0.4012 & 0.6444 & 0.5215 & 0.5829 \\
7 & 0.3419 & 0.5566 & 0.5623 & 0.3361 & 0.4492 \\
8 & 0.3995 & 0.3539 & 0.6570 & 0.5778 & 0.6174 \\
9 & 0.3372 & 0.3750 & 0.5546 & 0.5527 & 0.5536 \\
10 & 0.3333 & 0.4499 & 0.5482 & 0.4634 & 0.5058 \\
11 & 0.4032 & 0.3427 & 0.6630 & 0.5912 & 0.6271 \\
12 & 0.4113 & 0.3335 & 0.6764 & 0.6022 & 0.6393 \\
13 & 0.4227 & 0.4455 & 0.6952 & 0.4686 & 0.5819 \\
14 & 0.6080 & 0.3462 & 1 & 0.5871 & 0.7935 \\
15 & 0.4843 & 0.5657 & 0.7965 & 0.3252 & 0.5608 \\
16 & 0.5556 & 0.5415 & 0.9137 & 0.3541 & 0.6339 \\
\hline
\end{tabular}

Table 12. Response table for GAP scores for the Laser-Assisted Jet Electro-Chemical Machining (LA-JECM) process.

\begin{tabular}{lcccccc}
\hline \multicolumn{1}{c}{ Process parameter } & Level 1 & Level 2 & Level 3 & Level 4 & Max-min & Rank \\
\hline Supply voltage & 0.5603 & 0.5551 & 0.5815 & $\mathbf{0 . 6 4 2 5}$ & 0.0874 & 4 \\
Electrolyte concentration & 0.6073 & $\mathbf{0 . 6 3 8 6}$ & 0.5524 & 0.5412 & 0.0974 & 3 \\
Inter-electrode gap & $\mathbf{0 . 6 4 1 7}$ & 0.6108 & 0.6342 & 0.4528 & 0.1889 & 1 \\
Duty cycle & $\mathbf{0 . 6 5 1 2}$ & 0.6246 & 0.5707 & 0.4929 & 0.1583 & 2 \\
\hline
\end{tabular}

Table 13. ANOVA results for the Laser-Assisted Jet Electro-Chemical Machining (LA-JECM) process.

\begin{tabular}{lccccc}
\hline \multicolumn{1}{c}{ Source } & DoF & Adj SS & Adj MS & $\boldsymbol{F}$-value & contribution (\%) \\
\hline Supply voltage & 3 & 0.0193 & 0.0064 & 6.28 & 9.58 \\
Electrolyte concentration & 3 & 0.0254 & 0.0084 & 8.26 & 12.61 \\
Inter-electrode gap & 3 & 0.0951 & 0.0317 & 30.94 & 47.22 \\
Duty cycle & 3 & 0.0585 & 0.0195 & 19.05 & 29.07 \\
Error & 3 & 0.0030 & 0.0010 & - & 1.52 \\
Total & 15 & 0.2015 & - & - & - \\
\hline
\end{tabular}

JECM process at its fullest potential, the parametric combination should be maintained as supply voltage $=200 \mathrm{~V}$, electrolyte concentration $=40 \mathrm{~g} / \mathrm{l}$, interelectrode gap $=2 \mathrm{~mm}$, and duty cycle $=60 \%$, which can be represented as $A_{4} B_{2} C_{1} D_{1}$. It only differs from the previously obtained parametric setting of $A_{4} B_{2} C_{3} D_{1}$ with respect to inter-electrode gap. In the GC-EDAS method-based combination, the lower value of inter-electrode gap ( $2 \mathrm{~mm})$ is recommended. Malik and Manna [40] studied the effects of inter-electrode gap on the responses of the considered LA-JECM process and observed that the maximum value of MRR could be achieved at a lower inter-electrode gap. Hole taper would exhibit a decreasing trend pattern up to $3 \mathrm{~mm}$ inter-electrode gap and, then, start increasing.
On the other hand, SR value would be low at the lower inter-electrode gap and begin increasing upon an increase in the inter-electrode gap. The max-min column of Table 12 recognizes the inter-electrode gap as the most dominant process parameter in determination of GAP score. It is also supported by the ANOVA results, as shown in Table 13, which depicts that the inter-electrode gap has the highest contribution of $47.2 \%$ to estimating GAP scores. However, in the same process, applying GRA technique, Malik and Manna [40] obtained the optimal parametric mix as $A_{1} B_{2} C_{2} D_{1}$, which differed from the GC-EDAS method-based parametric combination with respect to supply voltage and inter-electrode gap.

Now, the corresponding regression models high- 
Table 14. Predicted responses for the Laser-Assisted Jet Electro-Chemical Machining (LA-JECM) process.

\begin{tabular}{lccc}
\hline Optimization approach & MRR & TAP & SR \\
\hline GC-EDAS approach $\left(A_{4} B_{2} C_{1} D_{1}\right)$ & 5.8952 & 4.2504 & 5.544 \\
GRA technique $\left(A_{1} B_{2} C_{2} D_{1}\right)[40]$ & 5.4938 & 5.342 & 8.5952 \\
Improvement $(\%)$ & 7.30 & 20.43 & 35.49 \\
\hline
\end{tabular}

lighting the relationships between the LA-JECM process parameters and responses are developed in Eqs. (25)-(27). Based on these equations, values of the three responses are computed at the obtained parametric combination and are compared with those of Malik and Manna [40] in Table 14. Improvements of $7.30 \%, 20.43 \%$, and $35.49 \%$ in MRR, TAP, and SR are respectively observed at the optimal parametric mix of $A_{4} B_{2} C_{1} D_{1}$ against those as determined in the parametric combination of $A_{1} B_{2} C_{2} D_{1}$. Lastly, a regression model relating the LA-JECM process parameters to GAP score is also developed. The corresponding surface plots, as portrayed in Figure 5, present the variations in GAP scores with respect to the considered LA-JECM process parameters.

$$
\begin{aligned}
M R R= & -7.94-0.0343 \times A+0.1467 \times B-3.47 \times \\
& C+0.329 \times D+0.000230 \times A^{2}-0.000203 \\
& \times B^{2}+0.235 \times C^{2}-0.00121 \times D^{2} \\
& -0.000081 \times A \times B-0.00221 \times A \\
& \times C+0.000145 \times A \times D+0.0226 \\
& \times B \times C-0.00227 \times B \times D \\
T A P= & -22.7-0.027 \times A-0.051 \times B-8.2 \\
& \times C+1.01 \times D+0.00050 \times A^{2}+0.000714 \\
& \times B^{2}+1.25 \times C^{2}-0.0041 \times D^{2} \\
& +0.0000610 \times A \times B-0.0138 \times A \\
& \times C-0.00098 \times A \times D+0.041 \times B \\
& \times C-0.0032 \times B \times D
\end{aligned}
$$

$$
\begin{array}{rl}
S R= & 71.5+0.396 \times A-0.586 \times B+11.0 \\
& \times C-2.58 \times D-0.00157 \times A^{2}+0.000228 \\
& \times B^{2}-0.62 \times C^{2}+0.0140 \times D^{2}+0.000560 \\
& \times A \times B-0.0107 \times A \times C+0.000303 \\
& \times A \times D-0.099 \times B \times C+0.0110 \\
& \times B \times D, \\
G A P & s c o r e=18.73+0.06466 \times A-0.3085 \times B \\
& +3.777 \times C-0.6433 \times D-0.000550 \times A^{2} \\
& -0.000369 \times B^{2}-0.5763 \times C^{2}+0.002653 \\
& \times D^{2}+0.000800 \times A \times B+0.01339 \times A \\
& \times C+0.000440 \times A \times D-0.01037 \times B \\
& \times C+0.004703 \times B \times D+0.000124 \times B \\
& \times C \times D-0.000003 \times A \times B \times C \times D
\end{array}
$$

\subsection{AWJD process}

Taking water jet pressure, the stand-off distance, and abrasive mass flow rate as the input process parameters, Nair and Kumanan [41] performed AWJD operation on Inconel 617 superalloy material. Three level variations were considered for each of the AWJD process parameters, as shown in Table 15. Implementing Taguchi's $L_{9}$ orthogonal array as the experimental design plan, Nair and Kumanan [41] performed nine experiments considering multiple responses namely Drill Rate (DR) (in mm/sec), Depth Averaged Radial Overcut (DARO), Top Overcut (TOC) (in mm), Bottom Overcut (BOC) (in $\mathrm{mm}$ ), Top Circularity (TC) (in

Table 15. Process parameters with levels for the Abrasive Water Jet Drilling (AWJD) process [41].

\begin{tabular}{lcccc}
\hline Process parameter & Unit & Level 1 & Level 2 & Level 3 \\
\hline Water jet pressure (A) & $\mathrm{MPa}$ & 250 & 300 & 350 \\
Standoff distance (B) & $\mathrm{Mm}$ & 1.5 & 3.0 & 4.5 \\
Abrasive mass flow rate (C) & $\mathrm{kg} / \mathrm{min}$ & 0.24 & 0.34 & 0.44 \\
\hline
\end{tabular}




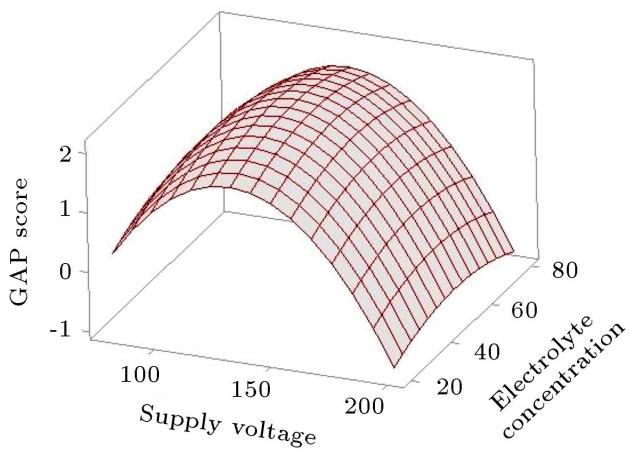

(a) GAP score vs. supply voltage, electrolyte concentration

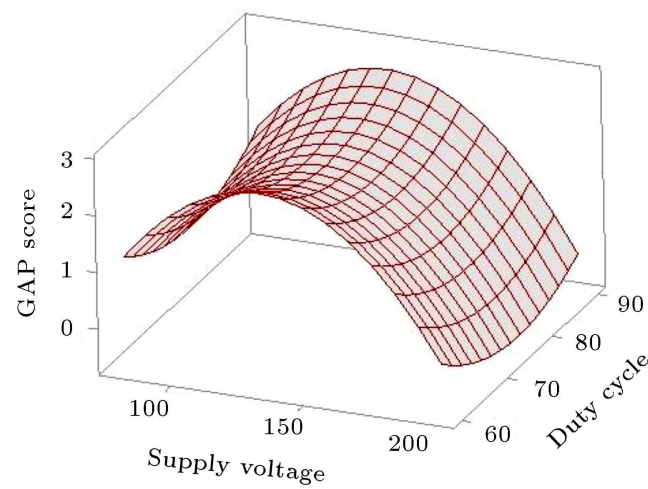

(c) GAP score vs. supply voltage, duty cycle

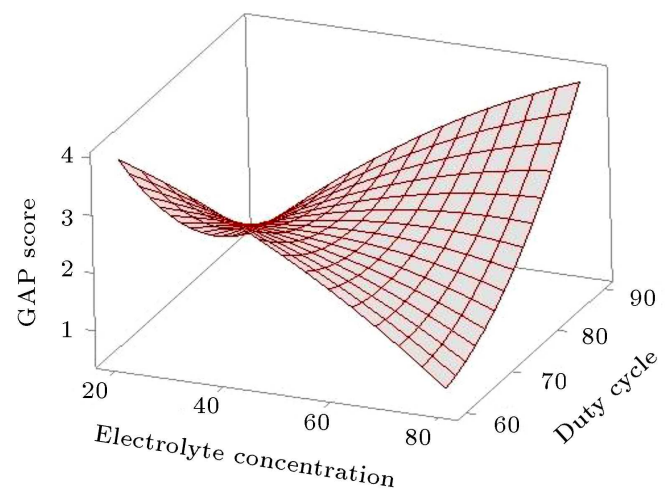

(e) GAP score vs. electrolyte concentration, duty cycle

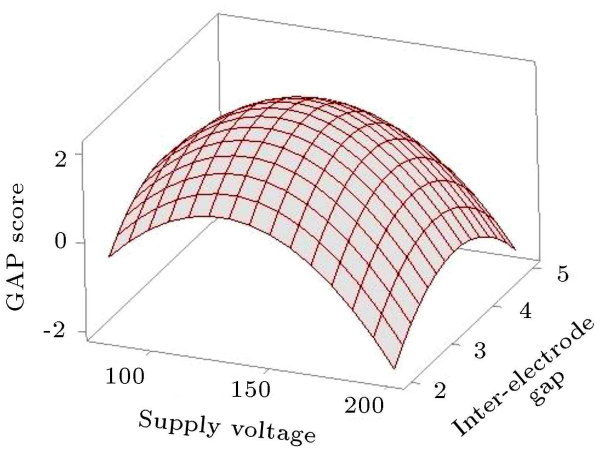

(b) GAP score vs. supply voltage, inter-electrode gap

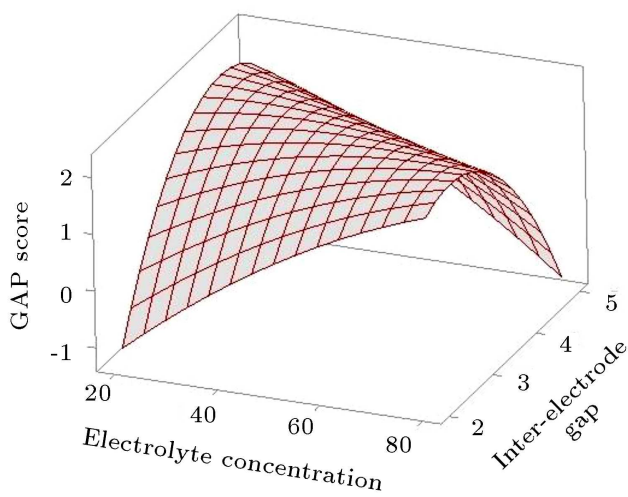

(d) GAP score vs. electrolyte concentration, inter-electrode gap

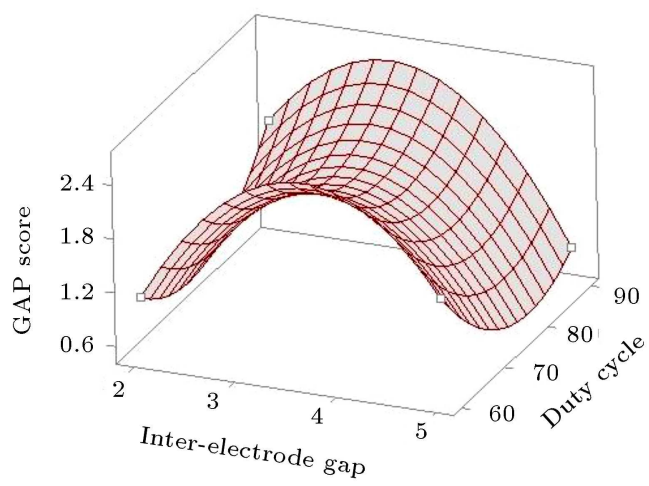

(f) GAP score vs. inter-electrode gap, duty cycle

Figure 5. Surface plots showing the effects of Laser-Assisted Jet Electro-Chemical Machining (LA-JECM) process parameters on GAP score.

$\mathrm{mm}$ ), Bottom Circularity (BC) (in mm), TAP (in degree), and $\mathrm{SR}$ (in $\mu \mathrm{m}$ ). Amongst those eight responses, DR is the sole larger-the-better characteristic, while the remaining seven are smaller-the-better characteristics. The experimental design plan along with the responses for all the nine experiments is provided in Table 16 . Employing multi-objective GRA technique, Nair and Kumanan [41] derived the most preferred parametric combination of the AWJD process as $A_{3} B_{1} C_{1}$ (water jet pressure $=350 \mathrm{MPa}$, stand-off distance $=3 \mathrm{~mm}$, and abrasive mass flow rate $=0.24 \mathrm{~kg} / \mathrm{min}$ ). This parametric optimization problem is now solved using the proposed GC-EDAS approach.

Now, following the same procedural steps of the previous two examples, the corresponding values of PDA and NDA are calculated in Table 17. The GCC values for the positive and negative distances are then estimated in Table 18 . Based on these 
Table 16. Experimental details of the Abrasive Water Jet Drilling (AWJD) process [41].

\begin{tabular}{cccccccccccc}
\hline Run & A & B & C & DR & DARO & TOC & BOC & TC & BC & TAP & SR \\
\hline 1 & 250 & 1.5 & 0.24 & 0.317 & 0.376 & 0.385 & 0.234 & 0.0416 & 0.0249 & 0.868 & 2.256 \\
2 & 250 & 3.0 & 0.34 & 0.377 & 0.397 & 0.429 & 0.225 & 0.0324 & 0.0288 & 1.172 & 2.904 \\
3 & 250 & 4.5 & 0.44 & 0.400 & 0.390 & 0.434 & 0.304 & 0.0376 & 0.0235 & 0.748 & 2.150 \\
4 & 300 & 1.5 & 0.34 & 0.426 & 0.409 & 0.394 & 0.278 & 0.0294 & 0.0301 & 0.665 & 2.460 \\
5 & 300 & 3.0 & 0.44 & 0.513 & 0.424 & 0.425 & 0.326 & 0.0324 & 0.0215 & 0.567 & 1.950 \\
6 & 300 & 4.5 & 0.24 & 0.408 & 0.394 & 0.401 & 0.254 & 0.0381 & 0.0282 & 0.842 & 2.611 \\
7 & 350 & 1.5 & 0.44 & 0.541 & 0.444 & 0.400 & 0.332 & 0.0189 & 0.0202 & 0.390 & 2.085 \\
8 & 350 & 3.0 & 0.24 & 0.444 & 0.408 & 0.383 & 0.227 & 0.0421 & 0.0253 & 0.897 & 2.009 \\
9 & 350 & 4.5 & 0.34 & 0.606 & 0.406 & 0.409 & 0.293 & 0.0624 & 0.0224 & 0.667 & 2.119 \\
\hline
\end{tabular}

Table 17. Positive and negative distances from the average for the Abrasive Water Jet Drilling (AWJD) process.

\begin{tabular}{|c|c|c|c|c|c|c|c|c|c|c|c|c|c|c|c|c|}
\hline \multirow[b]{2}{*}{ Run } & \multicolumn{8}{|c|}{ PDA } & \multicolumn{7}{|c|}{ NDA } & \multirow[b]{2}{*}{ SR } \\
\hline & DR & DARO & TOC & $\mathrm{BOC}$ & TC & $\mathrm{BC}$ & TAP & SR & DR & DARO & TOC & $\mathrm{BOC}$ & $\mathrm{TC}$ & $\mathrm{BC}$ & TAP & \\
\hline 1 & 0 & 0.0724 & 0.0533 & 0.1484 & 0 & 0.0036 & 0 & 0.0117 & 0.2924 & 0 & 0 & 0 & 0.1179 & 0 & 0.1461 & 0 \\
\hline 2 & 0 & 0.0206 & 0 & 0.1812 & 0.1293 & 0 & 0 & 0 & 0.1585 & 0 & 0.0549 & 0 & 0 & 0.1525 & 0.5475 & 0.2722 \\
\hline 3 & 0 & 0.0378 & 0 & 0 & 0 & 0.0596 & 0.0123 & 0.0581 & 0.1071 & 0 & 0.0672 & 0.1063 & 0.0105 & 0 & 0 & 0 \\
\hline 4 & 0 & 0 & 0.0311 & 0 & 0.2099 & 0 & 0.1219 & 0 & 0.0491 & 0.0090 & 0 & 0.0117 & 0 & 0.2045 & 0 & 0.0777 \\
\hline 5 & 0.1451 & 0 & 0 & 0 & 0.1293 & 0.1396 & 0.2513 & 0.1457 & 0 & 0.0461 & 0.0451 & 0.1864 & 0 & 0 & 0 & 0 \\
\hline 6 & 0 & 0.028 & 0.0139 & 0.0756 & 0 & 0 & 0 & 0 & 0.0893 & 0 & 0 & 0 & 0.0239 & 0.1285 & 0.1118 & 0.1438 \\
\hline 7 & 0.2076 & 0 & 0.0164 & 0 & 0.4921 & 0.1916 & 0.485 & 0.0866 & 0 & 0.0954 & 0 & 0.2082 & 0 & 0 & 0 & 0 \\
\hline 8 & 0 & 0 & 0.0582 & 0.1739 & 0 & 0 & 0 & 0.1199 & 0.0089 & 0.0066 & 0 & 0 & 0.1314 & 0.0124 & 0.1844 & 0 \\
\hline 9 & 0.3527 & 0 & 0 & 0 & 0 & 0.1036 & 0.1193 & 0.0717 & 0 & 0.0016 & 0.0057 & 0.0663 & 0.6769 & 0 & 0 & 0 \\
\hline
\end{tabular}

Table 18. Grey Correlation Coefficient (GCC) values for positive and negative distances for the Abrasive Water Jet Drilling (AWJD) process.

\begin{tabular}{|c|c|c|c|c|c|c|c|c|c|c|c|c|c|c|c|c|}
\hline \multirow[b]{2}{*}{ Run } & \multicolumn{8}{|c|}{ GP } & \multicolumn{7}{|c|}{ GN } & \multirow[b]{2}{*}{ SR } \\
\hline & DR & DARO & TOC & $\mathrm{BOC}$ & $\mathrm{TC}$ & $\mathrm{BC}$ & TAP & SR & DR & DARO & TOC & $\mathrm{BOC}$ & $\mathrm{TC}$ & $\mathrm{BC}$ & TAP & \\
\hline 1 & 0.3333 & 1 & 0.8554 & 0.7344 & 0.3333 & 0.3375 & 0.3333 & 0.3522 & 1 & 0.3333 & 0.3333 & 0.3333 & 0.3771 & 0.3333 & 0.4055 & 0.3333 \\
\hline 2 & 0.3333 & 0.4112 & 0.3333 & 1 & 0.4041 & 0.3333 & 0.3333 & 0.3333 & 0.5219 & 0.3333 & 0.7321 & 0.3333 & 0.3333 & 0.6628 & 1 & 1 \\
\hline 3 & 0.3333 & 0.5116 & 0.3333 & 0.3333 & 0.3333 & 0.4205 & 0.3391 & 0.4540 & 0.4411 & 0.3333 & 1 & 0.5054 & 0.3368 & 0.3333 & 0.3333 & 0.3333 \\
\hline 4 & 0.3333 & 0.3333 & 0.5182 & 0.3333 & 0.4658 & 0.3333 & 0.4004 & 0.3333 & 0.3754 & 0.3558 & 0.3333 & 0.3463 & 0.3333 & 1 & 0.3333 & 0.4117 \\
\hline 5 & 0.4593 & 0.3333 & 0.3333 & 0.3333 & 0.4041 & 0.6481 & 0.5092 & 1 & 0.3333 & 0.4915 & 0.6029 & 0.8266 & 0.3333 & 0.3333 & 0.3333 & 0.3333 \\
\hline 6 & 0.3333 & 0.4490 & 0.3966 & 0.4619 & 0.3333 & 0.3333 & 0.3333 & 0.3333 & 0.4185 & 0.3333 & 0.3333 & 0.3333 & 0.3414 & 0.5736 & 0.3859 & 0.5146 \\
\hline 7 & 0.5486 & 0.3333 & 0.4104 & 0.3333 & 1 & 1 & 1 & 0.5520 & 0.3333 & 1 & 0.3333 & 1 & 0.3333 & 0.3333 & 0.3333 & 0.3333 \\
\hline 8 & 0.3333 & 0.3333 & 1 & 0.9256 & 0.3333 & 0.3333 & 0.3333 & 0.7382 & 0.3403 & 0.3494 & 0.3333 & 0.3333 & 0.3829 & 0.3474 & 0.4299 & 0.3333 \\
\hline 9 & 1 & 0.3333 & 0.3333 & 0.3333 & 0.3333 & 0.5212 & 0.3987 & 0.496 & 0.3333 & 0.3372 & 0.3534 & 0.4232 & 1 & 0.3333 & 0.3333 & 0.3333 \\
\hline
\end{tabular}

data, the average weighted GCC values, normalized weighted GCC values, and GAP scores are determined, as provided in Table 19. From this table, it can be clearly noticed that the experiment number 8 with the maximum GAP score of 0.6284 and parametric setting of $A_{3} B_{2} C_{1}$ is identified as the optimal parametric mix for the considered AWJD process.

The calculated GAP scores are now adopted for developing the related response table and response graph, as depicted in Table 20 and Figure 6 respectively. From Table 20, it can be noticed that the optimal parametric mix for the considered AWJD process should be $A_{3} B_{1} C_{1}$, i.e., water jet pressure = $350 \mathrm{MPa}$, stand-off distance $=1.5 \mathrm{~mm}$, and abrasive mass flow rate $=0.24 \mathrm{~kg} / \mathrm{min}$. This optimal parametric combination derived using the GC-EDAS approach is exactly the same as that of Nair and Kumanan [41]. Thus, for the said AWJD operation, both the optimization approaches result in the same parametric mix, leading to the enhancement of the machining performance. The max-min values in Table 20 and the slopes for different AWJD process parameters in Figure 6 recognize water jet pressure as the most influential process parameter in computation of GAP scores. It can also be verified based on the ANOVA results of Table 21. The corresponding regression model relating AWJD process parameters to GAP score is also established, which finally helps in developing the 
Table 19. Computation of GAP scores for the Abrasive Water Jet Drilling (AWJD) process.

\begin{tabular}{cccccc}
\hline Run & GCP & GCN & NGCP & NGCN & $\begin{array}{c}\text { GAP } \\
\text { score }\end{array}$ \\
\hline 1 & 0.5349 & 0.4312 & 0.8265 & 0.2985 & 0.5625 \\
2 & 0.4353 & 0.6146 & 0.6725 & 0 & 0.3363 \\
3 & 0.3823 & 0.4521 & 0.5907 & 0.2645 & 0.4276 \\
4 & 0.3814 & 0.4361 & 0.5893 & 0.2904 & 0.4398 \\
5 & 0.5026 & 0.4485 & 0.7766 & 0.2703 & 0.5234 \\
6 & 0.3718 & 0.4042 & 0.5744 & 0.3423 & 0.4583 \\
7 & 0.6472 & 0.5 & 1 & 0.1865 & 0.5932 \\
8 & 0.5413 & 0.3562 & 0.8364 & 0.4204 & 0.6284 \\
9 & 0.4687 & 0.4309 & 0.7241 & 0.2989 & 0.5115 \\
\hline
\end{tabular}

Table 20. Response table for GAP scores for the Abrasive Water Jet Drilling (AWJD) process.

\begin{tabular}{lccccc}
\hline Process parameter & Level 1 & Level 2 & Level 3 & Max-min & Rank \\
\hline Water jet pressure & 0.4421 & 0.4739 & $\mathbf{0 . 5 7 7 7}$ & 0.1356 & 1 \\
Standoff distance & $\mathbf{0 . 5 3 1 9}$ & 0.496 & 0.4658 & 0.066 & 3 \\
Abrasive mass flow rate & $\mathbf{0 . 5 4 9 7}$ & 0.4292 & 0.5148 & 0.1205 & 2 \\
\hline
\end{tabular}

Table 21. ANOVA results of the Abrasive Water Jet Drilling (AWJD) process.

\begin{tabular}{lccccc}
\hline \multicolumn{1}{c}{ Source } & DoF & Adj SS & Adj MS & $\boldsymbol{F}$-value & Contribution (\%) \\
\hline Water jet pressure & 2 & 0.0302 & 0.0151 & 4.12 & 44.95 \\
Standoff distance & 2 & 0.0066 & 0.0033 & 0.90 & 9.77 \\
Abrasive mass flow rate & 2 & 0.0231 & 0.0115 & 3.15 & 34.37 \\
Error & 2 & 0.0073 & 0.0037 & - & 10.91 \\
Total & 8 & 0.0671 & - & - & - \\
\hline
\end{tabular}

surface plots, as exhibited in Figure 7.

$$
\begin{aligned}
& G A P \text { score }=3.085-0.007651 \times A-0.3689 \\
& \quad \times B-7.047 \times C+0.000014 \\
& \quad \times A^{2}+0.009237 \times B^{2} \\
& \quad+13.80 \times C^{2}+0.000932 \times A \\
& \quad \times B-0.007200 \times A \times C .
\end{aligned}
$$

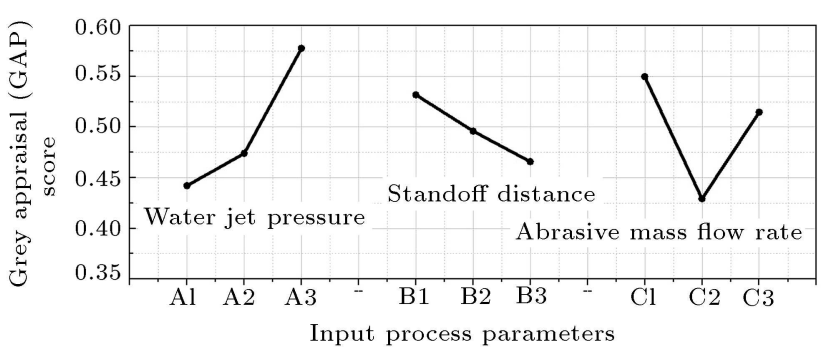

Figure 6. Response graph for GAP score for the Abrasive Water Jet Drilling (AWJD) process.

\section{Conclusions}

Selecting the optimal parametric combination for an Non-Traditional Machining (NTM) process is often considered as a difficult task for the concerned process engineer in order to achieve the desired responses. This paper proposes an integrated Grey Correlationbased EDAS (GC-EDAS) approach to identify the optimal combinations of different input parameters for three NTM processes, i.e., Photo-Chemical Machining (PCM), Laser-Assisted Jet Electro-Chemical Machining (LA-JECM), and Abrasive Water Jet Drilling (AWJD) processes. Based on the detailed analyses, it can be clearly concluded that this approach is capable of identifying better combinations of the input parameters for almost all the considered NTM processes. The predicted response values estimated from the developed regression models confirm their superiority over the other popular approaches, demonstrating their successful applicability as a multi-objective optimization tool. Thus, it can be concluded that the GC-EDAS 


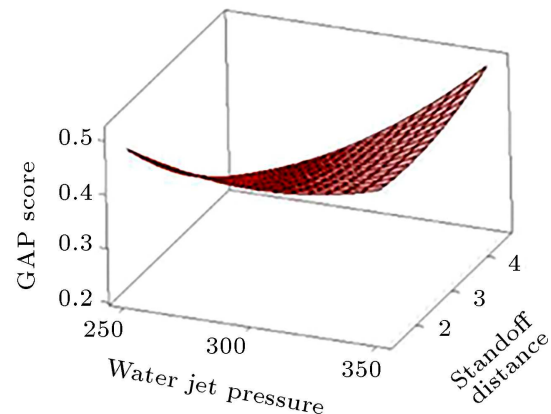

(a) GAP score vs. water jet pressure, stand-off distance

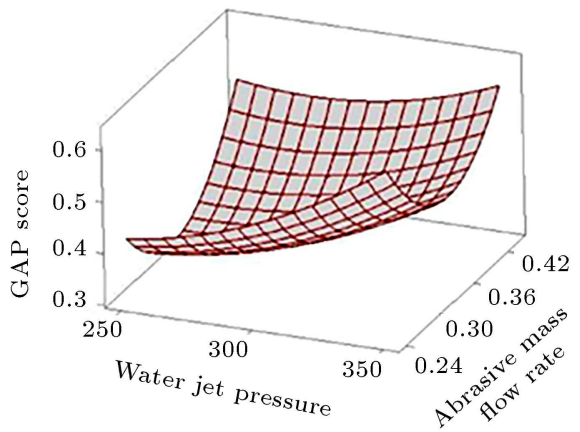

(b) GAP score vs. water jet pressure, abrasive mass flow rate

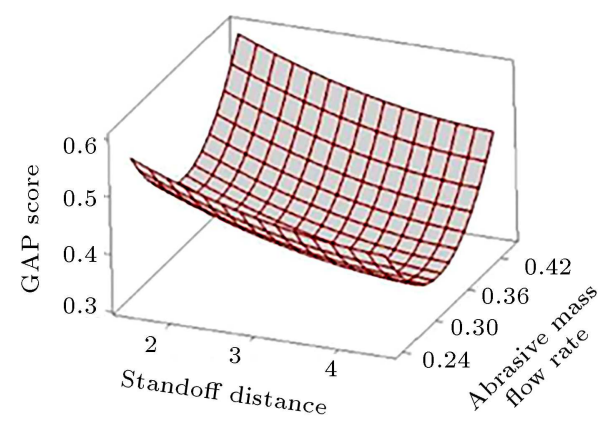

(c) GAP score vs. stand-off distance, abrasive mass flow rate

Figure 7. Surface plots showing the influences of Abrasive Water Jet Drilling (AWJD) process parameters on GAP score.

approach, being simple, mathematically sound and accurate, can be effectively employed for identification of the optimal parametric combinations of different NTM processes. It would help the concerned processes engineers to identify the best mix for a specific NTM process without relying on the operator's experience or manufacturer's data handbooks. As the parametric analyses are based on the data obtained from the past researchers; hence, there is no scope in this paper to conduct the necessary validation experiments. As the future scope of this paper, grey correlation method can also be integrated with other Multi-Criteria Decision Making (MCDM) methods to explore their applicability to parametric optimization of both conventional and non-conventional machining processes. This method can further be applied to other decision-making problems that deal with vulnerability and uncertainty in data sequences, leading to more accurate and robust results.

\section{References}

1. El-Hofy, H., Advanced Machining Processes: Nontraditional and Hybrid Machining Processes, McGraw-Hill, New York (2005).

2. Pandey, P.C. and Shan, H.S., Modern machining processes, Tata McGraw-Hill Publishing Company Limited, New Delhi (2005).
3. Aggarwal, A. and Singh, H. "Optimization of machining techniques - A retrospective and literature review", Sadhana, 30(6), pp. 699-711 (2005).

4. Chakraborty, S., Bhattacharyya, B., and Diyaley, S. "Applications of optimization techniques for parametric analysis of non-traditional machining processes: A review", Management Science Letters, 9(3), pp. 467494 (2019).

5. Huang, S.C. and Dao, T.P. "Multi-objective optimal design of a 2-DOF flexure-based mechanism using hybrid approach of grey-Taguchi coupled response surface methodology and entropy measurement", Arabian Journal for Science and Engineering, 41(12), pp. 5215-5231 (2016).

6. Dao, T.P. and Huang, S.C. "Optimization of a two degrees of freedom compliant mechanism using Taguchi method-based grey relational analysis", Microsystem Technologies, 23(10), pp. 4815-4830 (2017).

7. Prasad, S.R., Ravindranath, K., and Devakumar, M.L.S. "Experimental investigation and parametric optimization in abrasive jet machining on nickel 233 alloy using WASPAS and MOORA", Cogent Engineering, 5, 1497830 (2018). https://doi.org/10.1080/23311916.2018.1497830

8. Ananthakumar, K., Rajamani, D., Balasubramanian, E., et al. "Measurement and optimization of multiresponse characteristics in plasma arc cutting of Monel $400^{\mathrm{TM}}$ using RSM and TOPSIS", Measurement, 135, pp. $725-737$ (2019). 
9. Assarzadeh, S. and Ghoreishi, M. "Mathematical modeling and optimization of the electro-discharge machining (EDM) parameters on tungsten carbide composite: Combining response surface methodology and desirability function technique", Scientia Iranica., Transaction B, Mechanical Engineering, 22(2), pp. 539-560 (2015).

10. Ghorabaee, M.K., Zavadskas, E.K., Olfat, L., et al. "Multi-criteria inventory classification using a new method of evaluation based on distance from average solution (EDAS)", Informatica, 26(3), pp. 435-451 (2015).

11. Kahraman, C., Ghorabaee, M.K., Zavadskas, E.K., et al. "Intuitionistic fuzzy EDAS method: An application to solid waste disposal site selection", Journal of Environmental Engineering and Landscape Management, 25(1), pp. 1-12 (2017).

12. Ghorabaee, M.K., Amiri, M., Zavadskas, E.K., et al. "A new multi-criteria model based on interval type-2 fuzzy sets and EDAS method for supplier evaluation and order allocation with environmental considerations", Computers \& Industrial Engineering, 112, pp. 156-174 (2017).

13. Juodagalvienè, B., Turskis, Z., S̆aparauskas, J., et al. "Integrated multi-criteria evaluation of house's plan shape based on the EDAS and SWARA methods", Engineering Structures and Technologies, 9(3), pp. 117-125 (2017).

14. Li, Y.Y., Wang, J.Q., and Wang, T.L. "A linguistic neutrosophic multi-criteria group decision-making approach with EDAS method", Arabian Journal for Science and Engineering, 44(3), pp. 2737-2749 (2019).

15. Turskis, Z. and Juodagalviené, B. "A novel hybrid multi-criteria decision-making model to assess a stairs shape for dwelling houses", Journal of Civil Engineering and Management, 22(8), pp. 1078-1087 (2016).

16. Xia, X., Govindan, K., and Zhu, Q. "Analyzing internal barriers for automotive parts remanufacturers in China using grey-DEMATEL approach", Journal of Cleaner Production, 87, pp. 811-825 (2015).

17. Tian, G., Chu, J., and Qiang, T. "Influence factor analysis and prediction models for component removal time in manufacturing", Proceedings of the Institution of Mechanical Engineers, Part B: Journal of Engineering Manufacture, 227(10), pp. 1533-1540 (2013).

18. Kumar, K. and Agarwal, S. "Multi-objective parametric optimization on machining with wire electric discharge machining", International Journal of Advanced Manufacturing Technology, 62(5-8), pp. 617633 (2012).

19. Kolahan, F. and Moghaddam, M.A. "The use of Taguchi method with grey relational analysis to optimize the EDM process parameters with multiple quality characteristics", Scientia Iranica., Transaction B, Mechanical Engineering, 22(2), pp. 530-538 (2015).

20. Mohanty, C.P., Satpathy, M.P., Mahapatra, S.S., et al. "Optimization of cryo-treated EDM variables using
TOPSIS-based TLBO algorithm", Sadhana, 43(4), pp. 1-18 (2018).

21. Li, M., Yu, T., Yang, L., et al. "Parameter optimization during minimum quantity lubrication milling of TC4 alloy with graphene-dispersed vegetable-oil-based cutting fluid", Journal of Cleaner Production, 209, pp. 1508-1522 (2019).

22. Świercz, R., Oniszczuk-Świercz, D., and Chmielewski, T. "Multi-response optimization of electrical discharge machining using the desirability function", Micromachines, $\mathbf{1 0}(1), 25$ pages (2019). DOI: 10.3390/mi10010072

23. Das, P.P. and Chakraborty, S. "Parametric optimization of non-traditional machining processes using Taguchi method and super ranking concept", Yugoslav Journal of Operations Research, 29(2), pp. 249-271 (2019).

24. Agrawal, D. and Kamble, D. "Optimization of photochemical machining process parameters for manufacturing microfluidic channel", Materials and Manufacturing Processes, 34(1), pp. 1-7 (2018).

25. Sidhu, S.S. and Yazdani, M. "Comparative analysis of MCDM techniques for EDM of SiC/A359 composite", Arabian Journal for Science and Engineering, 43(3), pp. 1093-1102 (2018).

26. Chakraborty, S., Chatterjee, P., and Das, P.P. "A DoETOPSIS method-based meta-model for parametric optimization of non-traditional machining processes", Journal of Modelling in Management, 14(2), pp. 430455 (2019).

27. Ishfaq, K., Mufti, N.A., Ahmed, N., et al. "An investigation of surface roughness and parametric optimization during wire electric discharge machining of cladded material", International Journal of Advanced Manufacturing Technology, 97(9-12), pp. 4065-4079 (2018)

28. Baghel, R., Mali, H.S., and Biswas, S.K. "Parametric optimization and surface analysis of diamond grindingassisted EDM of $\mathrm{TiN}_{-} \mathrm{Al}_{2} \mathrm{O}_{3}$ ceramic composite", International Journal of Advanced Manufacturing Technology, 100(5-8), pp. 1183-1192 (2019).

29. Chakraborty, S. and Das, P.P. "A multivariate quality loss function approach for parametric optimization of non-traditional machining processes", Management Science Letters, 8(8), pp. 873-884 (2018).

30. Rao, R. and Yadava, V. "Multi-objective optimization of Nd: YAG laser cutting of thin superalloy sheet using grey relational analysis with entropy measurement", Optics \& Laser Technology, 41(8), pp. 922-930 (2009).

31. Tang, L. and Du, Y.T. "Experimental study on green electrical discharge machining in tap water of $\mathrm{Ti}$ $6 \mathrm{Al}-4 \mathrm{~V}$ and parameters optimization", International Journal of Advanced Manufacturing Technology, 70(14), pp. 469-475 (2014).

32. Jagadish, and Ray, A. "Optimization of process parameters of green electrical discharge machining using principal component analysis (PCA)", International 
Journal of Advanced Manufacturing Technology, 87(58), pp. 1299-1311 (2016).

33. Nadda, R., Kumar, R., Singh, T., et al. "Experimental investigation and optimization of cobalt bonded tungsten carbide composite by hybrid AHP-TOPSIS approach", Alexandria Engineering Journal, 57 (4), pp. 3419-3428 (2018).

34. Das, P.P., Diyaley, S., Chakraborty, S., et al. "Multiobjective optimization of wire electro discharge machining (WEDM) process parameters using grey-fuzzy approach", Periodica Polytechnica Mechanical Engineering, 63(1), pp. 16-25 (2019).

35. Chakraborty, S., Das, P.P., and Kumar, V. "Application of grey-fuzzy logic technique for parametric optimization of non-traditional machining processes", Grey Systems: Theory and Application, 8(1), pp. 4668 (2018).

36. Tian, G., Zhang, H., Feng, Y., et al. "Green decoration materials selection under interior environment characteristics: A grey-correlation based hybrid MCDM method", Renewable and Sustainable Energy Reviews, 81, pp. 682-692 (2018).

37. Jia, Z.Y., Ma, J.W., Wang, F.J., et al. "Characteristics forecasting of hydraulic valve based on grey correlation and ANFIS", Expert Systems with Applications, 37(2), pp. 1250-1255 (2010).

38. Huang, K.Y. and Jane, C.J. "A hybrid model for stock market forecasting and portfolio selection based on ARX, grey system and RS theories", Expert Systems with Applications, 36(3), pp. 5387-5392 (2009).

39. Zhou, Z.J. and Hu, C.H. "An effective hybrid approach based on grey and ARMA for forecasting gyro drift", Chaos, Solitons \& Fractals, 35(3), pp. 525-529 (2008).

40. Malik, A. and Manna, A. "Multi-response optimization of laser-assisted jet electrochemical machining parameters based on gray relational analysis", Journal of the Brazilian Society of Mechanical Sciences and Engineering, 40, 21 pages (2018). https://doi.org/10.1007/s40430-018-1069-9
41. Nair, A. and Kumanan, S. "Optimization of size and form characteristics using multi-objective grey analysis in abrasive water jet drilling of Inconel 617", Journal of the Brazilian Society of Mechanical Sciences and Engineering, 40, 15 pages (2018). https://doi.org/10.1007/s40430-018-1042-7

\section{Biographies}

Partha Protim Das is currently working as an Assistant Professor at the Department of Mechanical Engineering, Sikkim Manipal Institute of Technology, Sikkim, India. He obtained his BSc degree in Mechanical Engineering in 2013 from Annamalai University and his MS degree in 2015 from Mechanical Engineering Department, National Institute of Technology Silchar. His research interests lie in the areas of applications of different optimization techniques in machining and engineering environment. He has published numerous papers in national and international journals and is also a regular reviewer of various international journals of repute.

Shankar Chakraborty is a Professor at the Production Engineering Department of Jadavpur University. He was graduated in 1986 from University of Calcutta and obtained his postgraduate degree from Jadavpur University in 1989. He was awarded with PhD (Eng.) degree from Jadavpur University in 1994. His research interests include applications of different multi-criteria decision-making methods in manufacturing environment, control chart pattern recognition, and development of MIS and ERP systems for diverse engineering applications. He has guided several ME and $\mathrm{PhD}$ (Eng.) theses and published numerous papers in international journals. He is also a regular reviewer of several journals of international repute. 